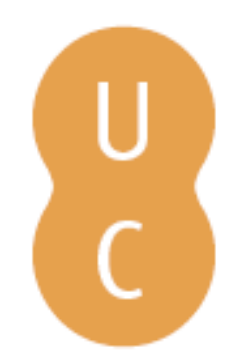

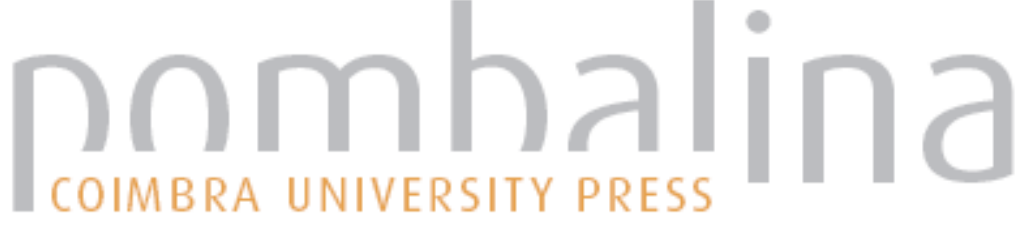

\section{Afetação multicritério de recursos a portefólios de atividades da REFER}

Autor(es): $\quad$ Mateus, Ricardo; Ferreira, José A. Antunes; Lourenço, João

Publicado por: Imprensa da Universidade de Coimbra

URL

persistente:

URI:http://hdl.handle.net/10316.2/35935

DOI:

DOI:http://dx.doi.org/10.14195/978-989-26-0738-2_14

Accessed : $\quad$ 26-Apr-2023 09:42:02

A navegação consulta e descarregamento dos títulos inseridos nas Bibliotecas Digitais UC Digitalis, UC Pombalina e UC Impactum, pressupõem a aceitação plena e sem reservas dos Termos e Condições de Uso destas Bibliotecas Digitais, disponíveis em https://digitalis.uc.pt/pt-pt/termos.

Conforme exposto nos referidos Termos e Condições de Uso, o descarregamento de títulos de acesso restrito requer uma licença válida de autorização devendo o utilizador aceder ao(s) documento(s) a partir de um endereço de IP da instituição detentora da supramencionada licença.

Ao utilizador é apenas permitido o descarregamento para uso pessoal, pelo que o emprego do(s) título(s) descarregado(s) para outro fim, designadamente comercial, carece de autorização do respetivo autor ou editor da obra.

Na medida em que todas as obras da UC Digitalis se encontram protegidas pelo Código do Direito de Autor e Direitos Conexos e demais legislação aplicável, toda a cópia, parcial ou total, deste documento, nos casos em que é legalmente admitida, deverá conter ou fazer-se acompanhar por este aviso. 


\section{INVESTIGAÇÃO OPERACIONAL EM AÇÃO \\ CASOS DE APLICAÇÃO}

RUI CARVALHO OLIVEIRA JOSÉ SOEIRO FERREIRA (EDITORES)

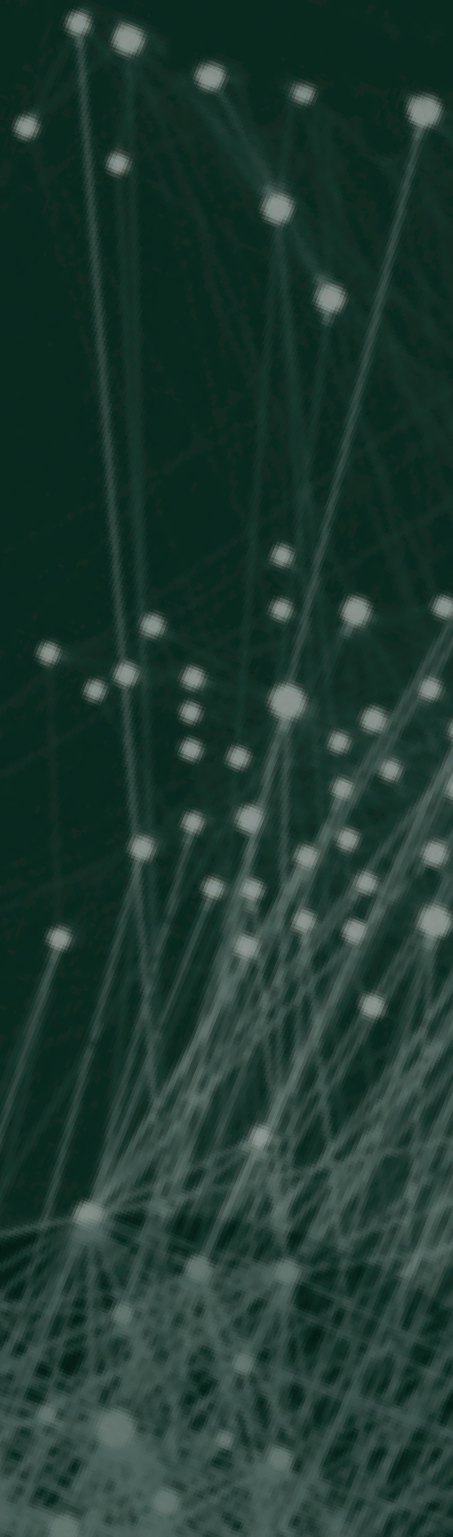




\section{CASO 14}

\section{AFETAÇÃo MULTICRITÉRIO DE RECURSOS A PORTEFÓLIOS DE ATIVIDADES DA REFER}

Ricardo Mateus Centro de Estudos de Gestão do IST (CEG-IST), Instituto Superior Técnico Universidade de Lisboa, ricardo.mateus@sapo.pt

José A. Antunes Ferreira CESUR-IST, Instituto Superior Técnico Universidade de Lisboa, antunes.ferreira@tecnico.ulisboa.pt

João Lourenço Centro de Estudos de Gestão do IST (CEG-IST), Instituto Superior Técnico Universidade de Lisboa, joao.lourenco@tecnico.ulisboa.pt 


\section{RESUMO}

O Plano de Atividades de uma organização é o instrumento de gestão que define, para um determinado período de tempo, os objetivos a atingir, as atividades a desenvolver e os recursos a afetar a essas atividades. Os recursos disponíveis para a implementação do Plano tipicamente não permitem realizar todas as atividades de interesse para a organização, o que obriga à existência de um processo de seleção de atividades. Neste contexto de restrição de recursos, a elaboração de um Plano de Atividades consiste num processo de seleção do portefólio de atividades que mais benefícios pode gerar para a organização face aos recursos que consome. Neste artigo apresenta-se a metodologia multicritério de apoio à decisão de afetação de recursos preconizada para a elaboração do Plano de Atividades da Direção Geral de Engenharia da REFER. A metodologia apresentada integra técnicas e ferramentas de índole técnica (tais como, os mapas cognitivos, a análise multicritério, o método MACBETH e a afetação de recursos com o Equity) e social (como é o caso das conferências de decisão). Neste enquadramento, o papel do apoio à decisão é o de clarificar, modelar e integrar as diferentes perspetivas existentes no processo de seleção do portefólio de atividades, através do desenvolvimento de uma linguagem de comunicação comum e de uma estrutura formal de interação entre os diversos atores da REFER (decisores e técnicos especialistas), seguindo uma abordagem construtiva e de aprendizagem, conducente à recomendação das atividades a incluir no Plano.

\section{PALAVRAS-ChAVE}

Análise de decisão multicritério; Afetação multicritério de recursos; Análise de portefólios de atividades. 


\section{Introdução}

A REFER é a empresa pública responsável pela administração da rede ferroviária portuguesa, que em 2005 se estendia ao longo de 3.613 km, dos quais $2.839 \mathrm{~km}$ com tráfego ferroviário. A REFER desenvolve a sua atividade em duas áreas principais: a gestão da infraestrutura, que inclui a sua conservação, manutenção e exploração; e a construção, instalação e renovação da infraestrutura.

Como entidade pública, a REFER está obrigada à elaboração de planos de atividade anuais e plurianuais, levando em consideração os objetivos estratégicos estabelecidos pela tutela para o setor em que opera. Um Plano de Atividades estabelece os objetivos a alcançar, as atividades em curso e planeadas e os recursos necessários para as desenvolver.

No final de outubro de 2005, tomou posse um novo Conselho de Administração, que teve de definir e aprovar num curto espaço de tempo o Plano de Atividades da REFER para o ano seguinte. Para o efeito, o Conselho solicitou à Direção Geral de Engenharia (DGEN), responsável pela área de construção, instalação e renovação da infraestrutura (Figura 1; REFER, 2005a), a listagem das atividades em curso e planeadas para 2005, juntamente com uma breve caracterização das mesmas. O novo Conselho transmitiu a necessidade de definir objetivos, custos e indicadores para a seleção e priorização das atividades a incluir no respetivo Plano de Atividades (Monteiro, 2006). De acordo com as diretrizes da tutela, o Conselho transmitiu também como orientação prioritária a dinamização de uma política de contenção de custos (REFER, 2005b).

De acordo com as normas internas e procedimentos vigentes (REFER, 2004), o Plano de Atividades da DGEN (daqui em diante designado por Plano) deveria ser preparado tendo por base as orientações estratégicas emanadas pelo Conselho. A partir das orientações e informações recebidas, o Diretor Geral da DGEN deveria identificar as prioridades de investimento em conjunto com as diversas Direções da DGEN e em estreita colaboração com os restantes órgãos da empresa (Figura 1; REFER, 2004). Após a sua elaboração, o Plano deveria ser submetido para aprovação ao Conselho de Administração. 


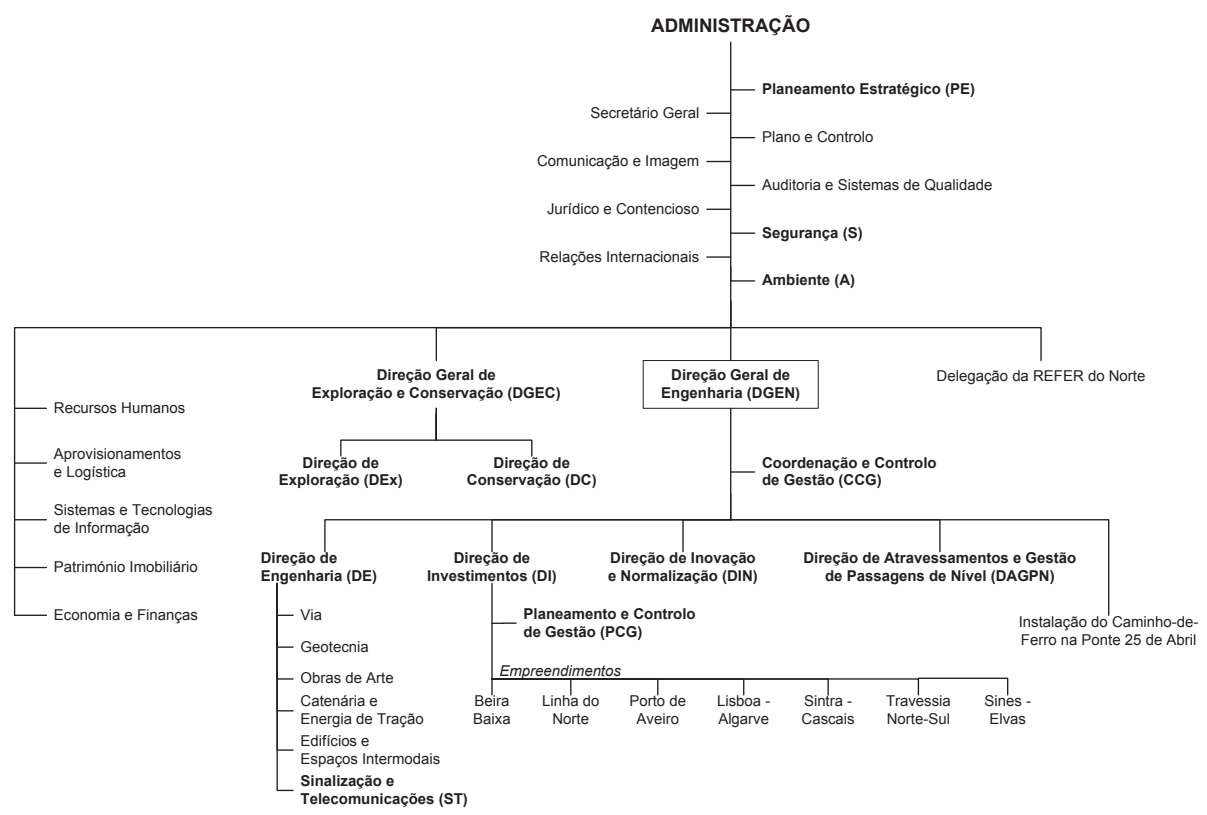

Figura 1: Estrutura organizacional da REFER

O procedimento para a elaboração de cada Plano anual consistia genericamente em adicionar novas atividades, propostas pelos diversos órgãos da empresa e previamente aprovadas a nível superior, ao conjunto de atividades em curso ou planeadas em anos anteriores. Embora o procedimento adotado pela REFER pareça intuitivamente correto, de facto padece de um conjunto de problemas identificados na literatura da análise de decisão relativa à afetação multicritério de recursos, tais como:

- Não coloca em causa atividades selecionadas anteriormente, mantendo atividades com benefícios marginais apenas porque no passado já se investiu nelas, ao invés de considerar em cada avaliação apenas os custos e benefícios que as atividades podem gerar no futuro (Hammond et al. (2006) designam esta prática como a armadilha dos custos afundados);

- Não quantifica de forma clara os benefícios das diversas atividades de forma a criar as condições para uma melhor tomada de decisão; 
- Não fundamenta, perante terceiros (externos ou internos), os benefícios que as diversas atividades podem gerar o que vai contra a transparência e responsabilização necessárias em decisões que afetam múltiplos atores;

- Considera apenas os benefícios que as atividades podem gerar, sem atender aos custos dessas atividades, promovendo um conjunto de atividades que não garante a melhor afetação dos recursos;

- Fomenta a criação de "silos» onde cada Direção propõe o maior número de atividades na esperança de conseguir a aprovação de uma parte proporcional. Por outro lado, a melhor afetação de recursos disponíveis na ótica de cada uma das Direções não implica que essa afetação seja a melhor na perspetiva global da DGEN (Phillips e Bana e Costa, 2007).

Estamos assim perante um problema típico de afetação multicritério de recursos, cuja resolução deve levar em consideração os benefícios das atividades (avaliados de acordo com os objetivos estratégicos da REFER), os trade-offs entre os objetivos, os recursos consumidos por essas atividades e o limite dos recursos disponibilizados à REFER pelo Estado para o efeito.

Face a esta realidade, o Diretor Geral da DGEN aproveitou a necessidade de elaborar o Plano de Atividades de 2006 como uma oportunidade para melhorar qualitativamente o processo de elaboração dos Planos de Atividades. Para o efeito, convidou os autores deste artigo para desenvolver e aplicar uma metodologia de apoio à decisão adequada à resolução deste problema. A metodologia preconizada baseia-se numa abordagem sociotécnica que inclui aspetos de natureza:

- técnica - sustentada num modelo de afetação de recursos, priorização e orçamentação (Phillips e Bana e Costa, 2007) que utiliza de forma integrada diversos métodos da análise de decisão, tais como a teoria de valor multicritério (Belton e Stewart, 2002), a estruturação de problemas centrada nos valores (Keeney, 1992) e a modelação do risco e incerteza (Clemen, 1996);

- $\quad$ e social - sustentada num processo construtivo de conferências de decisão (Phillips, 2007) com os atores-chave designados pela REFER, 
em que os autores agem exclusivamente como facilitadores, intervindo apenas no contexto e não nos conteúdos, modelando e integrando dados factuais e juízos de valor expressos pelos atoreschave.

A escolha deste tipo de abordagem de apoio à decisão fundamenta-se nas seguintes convicções (Bana e Costa, 1993b; Phillips e Bana e Costa, 2007):

a) uma convicção de base é que a estruturação e modelação do problema centrada nos valores e preferências dos decisores, considerando o risco e a incerteza, potenciam a tomada de decisões de qualidade;

b) a outra convicção fundamental reside no processo de apoio à decisão, que visa a construção de uma linguagem de comunicação comum e de uma estrutura formal de avaliação construtiva e de aprendizagem entre os diversos atores deste problema de decisão.

Como resultado da aplicação desta metodologia obteve-se um modelo multicritério de afetação de recursos que serviu para a DGEN utilizar como ferramenta de apoio à seleção do portefólio de atividades a incluir no seu Plano de Atividades.

A metodologia preconizada fundamentou-se em três fases fundamentais (Bana e Costa, 1992b e 1993a), decompostas nas seguintes etapas (ver Figura 2) que são desenvolvidas nas secções indicadas entre parênteses:

- Fase de Estruturação do problema de uma forma interativa e partilhada entre os diversos intervenientes no processo de decisão:

- Contextualização do problema (Secção 2);

- Identificação, estruturação e caracterização das atividades (Secção 3);

- Estimação dos custos de investimento das atividades (Secção 4);

- Identificação e estruturação dos objetivos estratégicos (Secção 5);

- Definição de descritores de impactos (Secção 6);

○ $\quad$ Estimação dos impactos das atividades (Secção 7); 
- Fase de Avaliação seguindo uma abordagem transparente, construtiva e de aprendizagem, sem a pretensão de assumir um posicionamento otimizante e normativo:

- Avaliação dos benefícios parciais das atividades (Secção 8);

- Ponderação dos objetivos (Secção 9);

- Avaliação dos benefícios globais das atividades (Secção 10);

- Fase de Recomendações relativamente à seleção do portefólio de atividades a incluir no Plano:

- Seleção de um portefólio de atividades eficiente que não ultrapasse a capacidade orçamental disponível para 2006 (Secção 11).

Sublinhe-se porém que em qualquer momento do processo de apoio à decisão é possível voltar a uma etapa anterior, para incluir elementos adicionais de informação ou rever juízos de valor.

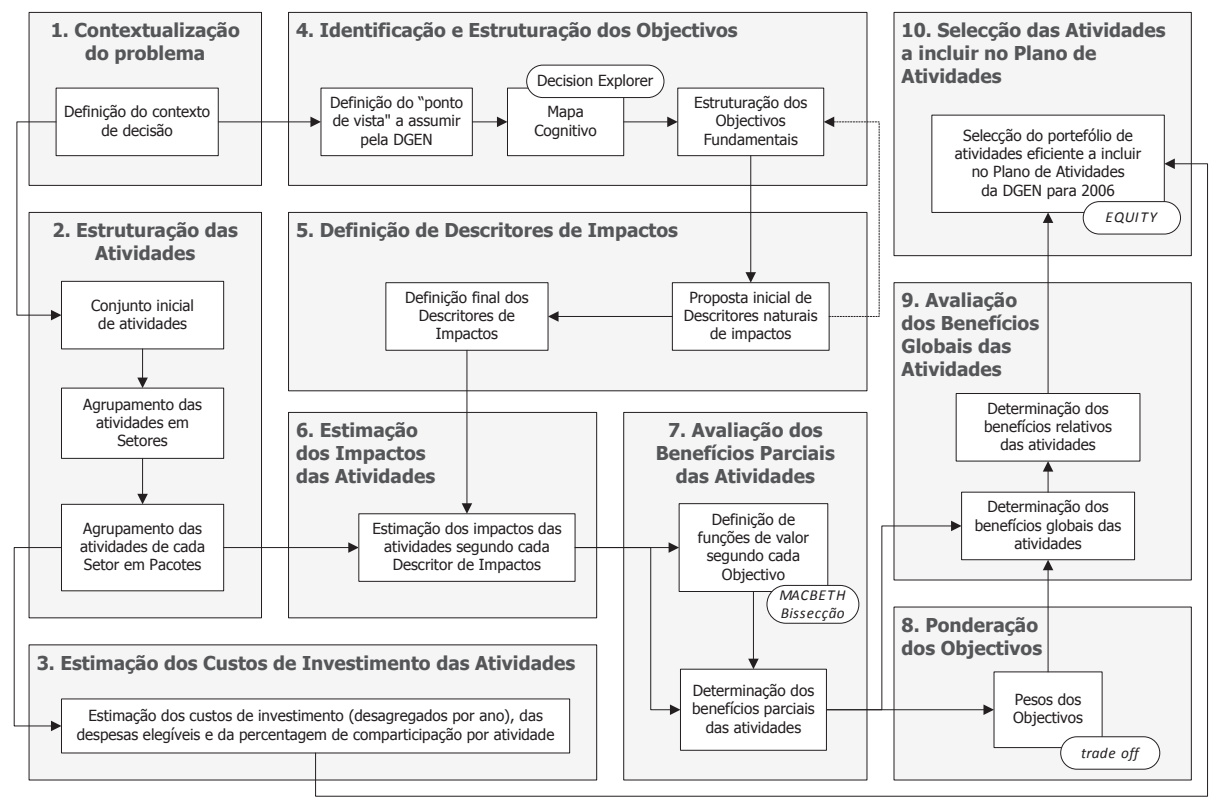

Figura 2: Síntese da metodologia 


\section{Contextualização do problema}

A fase de estruturação iniciou-se com a caracterização do contexto de decisão. Os principais atores envolvidos no processo de elaboração do Plano incluíam o Conselho de Administração, o Diretor Geral da DGEN (DG), os principais Diretores da REFER e vários técnicos da empresa com conhecimento tácito relativamente ao negócio ou com acesso a informação essencial para o processo de avaliação. Dois técnicos qualificados do PCG foram designados para apoiar a tempo inteiro os facilitadores deste processo sob a supervisão do DG. De entre as várias condicionantes (temporais, financeiras, administrativas, tecnológicas e legais) existentes, a conclusão do Plano no prazo de um mês foi desde logo identificada como um dos fatores críticos de sucesso deste processo de apoio à decisão.

O Plano de Atividades de 2005 constituiu a principal base de trabalho para a elaboração do Plano de Atividades de 2006. A estrutura desse Plano espelhava de certa forma a estrutura organizacional da empresa e o grau de responsabilidade de cada órgão relativamente à proposição e execução das diversas atividades da empresa. Cada órgão era responsável por um conjunto de programas. Cada programa consistia num conjunto de atividades agregadas em função da sua natureza. No total, o Plano continha assim 34 programas de atividades da responsabilidade de seis Direções: 9 da DI; 4 da DAGPN; 10 da ST; 5 da DE; 3 da DIN; 2 da DGEN; e 1 da responsabilidade conjunta da DI e DE. Os Diretores destas seis Direções, sob a liderança do DG, representam assim os Decisores neste processo de decisão (doravante identificados simplesmente por Decisores).

Após a apreensão do contexto de decisão estabeleceu-se o processo social que devia ser seguido para alcançar os resultados pretendidos. A conceção deste processo é essencial em contextos organizacionais como o da REFER, caracterizado pela existência de múltiplos intervenientes que podem influenciar as decisões (Administração, tutela, Diretores, técnicos, operadores ferroviários, sociedade em geral, etc.) com agendas, valores, preferências e poderes bastante diversos e por vezes conflituantes. Observe-se que, por um lado, numa estrutura organizacional como a da REFER, um único decisor não tem a capacidade de conhecer a multiplicidade de efeitos e consequências que cada 
atividade pode gerar, uma vez que a informação e conhecimento necessários para o efeito se encontram disseminados pelas diversas estruturas organizacionais, respetivos técnicos, e sistemas de informação da empresa. Por outro lado, os decisores competem entre si pelos mesmos recursos, que são limitados. Para que os decisores estejam alinhados e comprometidos com a implementação das atividades pelas quais são responsáveis é essencial que lhes seja demonstrada a racionalidade das decisões tomadas, de uma forma transparente e rastreável (suportada em evidências documentais) e desejavelmente através de um processo participativo e colaborativo de decisão em que a sua voz seja ouvida e levada em consideração.

\section{Identificação, estruturação e caracterização das atividades}

Considerou-se vantajoso agregar as atividades em setores. Um setor corresponde a um órgão (por exemplo, uma Direção) ou uma área estratégica (por exemplo, uma Linha) que compete por recursos e que funciona de forma independente em relação aos outros setores, ou seja, a proposição e execução das atividades de um determinado setor não dependem das iniciativas tomadas nos restantes setores. Por essa razão, as atividades foram agrupadas em 15 setores distintos da seguinte forma (a Direção responsável por cada setor é indicada entre parênteses):

- $\quad$ Setor S1 - Intervenção na Linha do Norte (DI);

- $\quad$ Setor S2 - Intervenção na Beira Baixa (DI);

- $\quad$ Setor S3 - Ligação ao Algarve (DI);

- $\quad$ Setor S4 - Melhoria das condições de exploração ferroviária (DI);

- Setor S5 - Missão para intervenções artísticas nas estações e interfaces (DGEN);

- $\quad$ Setor S6 - Consolidação das acessibilidades urbanas na margem Sul (DI);

- $\quad$ Setor S7 - Intervenção na Linha de Cintura e Linha de Sintra (DI);

- $\quad$ Setor S8 - Intervenção na Linha de Cascais (DI);

- $\quad$ Setor S9 - Ligação ferroviária Porto de Sines - Espanha (DI);

- $\quad$ Setor S10 - Acessibilidades Portuárias e Industriais (DI); 
- $\quad$ Setor S11 - Atividades da Direção de Atravessamentos e Gestão de PN's (DAGPN);

- Setor S12 - Atividades da Direção de Sinalização e Telecomunicações (ST);

- $\quad$ Setor S13 - Atividades da Direção de Engenharia (DE);

- Setor S14 - Atividades da Direção de Inovação e Normalização (DIN);

- $\quad$ Setor S15 - Atividades da Direção Geral de Engenharia (DGEN).

As atividades só têm sentido para uma organização como um meio para alcançar os seus objetivos. No entanto, atividades como a elaboração de um estudo ou do projeto de execução de uma linha ferroviária apenas geram impactos após a execução da respetiva obra. Por conseguinte, foi necessário adicionar atividades que incorporassem no modelo os impactos que só ocorrem após a efetiva implementação da respetiva obra. Por exemplo, quando existia apenas a atividade relacionada com a fase de estudos de uma linha ferroviária, foram adicionadas duas novas atividades, uma relativa ao projeto de execução e outra à execução da obra propriamente dita. Note-se que, no exemplo apresentado, todas as atividades consomem recursos, i.e. têm custos de investimento específicos, mas apenas a última atividade (execução da obra) gera impactos positivos (benefícios).

Desde o início, algumas Direções manifestaram a sua preocupação relativamente à possibilidade de o modelo de apoio à decisão vir a recomendar uma solução que passasse, por um lado, pela seleção de algumas atividades que contrariassem ordens e prioridades de nível superior existentes ao nível de cada setor e, por outro lado, pela não realização de quaisquer atividades (e inclusive o seu cancelamento) em alguns dos setores.

A primeira preocupação foi resolvida considerando como regra, por setor, a que o modelo deveria obedecer, que as atividades seriam agrupadas em pacotes de atividades, de acordo com a classificação que se apresenta na Tabela 1, pela respetiva Direção, e que só seriam selecionadas atividades de um pacote de nível superior após a seleção de todas as atividades incluídas em pacote(s) de nível(is) inferior(es). Note-se porém que isto não significa que se 
tenha de se selecionar todas as atividades incluídas num determinado pacote em simultâneo. Cada atividade será selecionada individualmente com base numa avaliação do seu próprio mérito.

A segunda preocupação foi atendida impondo como regra adicional que as atividades incluídas no Pacote P1, de cada setor, nunca seriam colocadas em causa, devido aos custos colaterais que uma decisão nesse sentido teria para a REFER (por exemplo, o pagamento de indemnizações por quebra de contrato ou a quebra da reputação da REFER como entidade de bem e credível na qual o mercado pode confiar). Face à imposição desta regra, deixou de ser relevante a determinação dos benefícios destas atividades, no entanto os respetivos custos a incorrer foram considerados pois tinham impacto no orçamento disponível.

Tabela 1: Pacotes e atividades

\begin{tabular}{|c|c|c|}
\hline Pacote & Descrição do pacote & N. ${ }^{\circ}$ atividades \\
\hline P1 & Atividades em curso e/ou indispensáveis & 101 \\
\hline $\mathrm{P} 2$ & Atividades a realizar por indicação do Estado & 10 \\
\hline P3 & Atividades importantes ao nível da segurança & 18 \\
\hline $\mathrm{P} 4$ & Atividades com compromissos externos já assumidos & 21 \\
\hline $\mathrm{P} 5$ & Atividades importantes com prioridade de primeira ordem & 29 \\
\hline P6 & Atividades importantes com prioridade de segunda ordem & 9 \\
\hline \multirow[t]{2}{*}{ P7 } & Atividades importantes com prioridade de terceira ordem & 11 \\
\hline & Total & 199 \\
\hline
\end{tabular}

Uma vantagem essencial deste tipo de estruturação em pacotes (Bana e Costa et al., 2002) é a de que permite modelar prioridades resultantes quer de preferências dos Decisores em relação à realização de algumas atividades em detrimento de outras quer da existência de vários tipos de restrições temporais entre atividades, em especial os quatro tipos de relações de sequencialidade entre pares de atividades (Fim-Princípio, Princípio-Princípio, Fim-Fim e FimPrincípio). Por exemplo, no setor S1, existe uma relação de sequencialidade do tipo Fim-Princípio entre a realização das atividades de projeto (P01-0-180) e de execução da obra (P01-0-181), ambas da estação do Entroncamento, pelo que a primeira atividade (projeto de execução) foi classificada no pacote P6 e a 
segunda atividade (execução da obra) foi classificada no pacote P7, ou seja, a segunda atividade só poderia iniciar-se após a conclusão da primeira. Outro exemplo, ainda relativo ao setor 1, consiste numa relação de sequencialidade do tipo Fim-Fim existente entre a atividade de implementação da sinalização, telecomunicações e edifício técnico de Santa Cita e a atividade de implementação do convel, ambas do ramal de Tomar. Neste caso, ambas as atividades foram agrupadas num mesmo pacote para que estas pudessem terminar no mesmo período temporal.

Adicionalmente, as atividades foram caracterizadas pelas Direções a um nível de pormenor que incluía:

- A sua descrição inequívoca em termos do objeto e âmbito que compreendiam (O quê)?;

- $\quad$ A delimitação territorial abrangida pela intervenção (Onde?);

- Uma estimativa plausível dos custos totais de implementação (desagregados em função das suas fontes de financiamento, nomeadamente: recursos públicos centrais, comunitários ou recursos próprios) e de exploração e manutenção (Quanto?);

- Uma estimativa plausível da sua duração, incluindo relações de sequencialidade (Quando?);

- A definição explícita do órgão responsável pela sua implementação (Quem?).

\section{Estimação dos custos de investimento das atividades}

A decisão de realização de qualquer atividade implica um custo de investimento que deve desejavelmente ser conhecido a priori.

Para esse efeito, foram estimados os custos totais de investimento de todas as atividades do Plano, desagregados temporalmente (por ano) e em função da sua fonte de financiamento (comunitária ou nacional), tal como se apresenta, a título de exemplo, na Tabela 2, para algumas atividades do Plano.

O custo total de uma atividade corresponde ao investimento total associado à realização dessa atividade. No entanto, a priori só é possível obter uma estimativa desse custo total. Neste processo admitiram-se dois tipos de estimativas para esse custo: pontual (o custo total esperado); ou através de um 
intervalo que compreendesse todos os custos plausíveis (sendo neste caso posteriormente utilizado o ponto médio do intervalo como estimativa do custo total). Esta última possibilidade revelou-se taticamente bastante útil, nomeadamente para desbloquear situações em que não foi possível obter de uma ou várias fontes de informação um custo total esperado.

Tabela 1: Custos totais de investimento por atividade (em milhares de euros)

\begin{tabular}{|c|c|c|c|c|c|c|c|c|c|}
\hline \multirow{2}{*}{$\begin{array}{l}\text { Código da } \\
\text { Atividade }\end{array}$} & \multirow{2}{*}{ Pacote } & \multicolumn{5}{|c|}{ Custos a incorrer } & \multirow{2}{*}{$\begin{array}{r}\text { Custo } \\
\text { total }\end{array}$} & \multirow{2}{*}{$\begin{array}{r}\text { Despesas } \\
\text { elegíveis }\end{array}$} & \multirow{2}{*}{$\begin{array}{c}\% \text { de } \\
\text { compart. }\end{array}$} \\
\hline & & 2006 & 2007 & 2008 & anos seg. & indeterm. & & & \\
\hline P01-0-010 & P1 & 205 & & & & & 205 & & \\
\hline P01-0-015 & P6 & & 4.041 & 5.600 & 5.200 & & 14.841 & & \\
\hline P01-0-020 & P4 & 500 & 500 & & & & 1.000 & & \\
\hline P01-0-025 & $\mathrm{P} 1$ & 641 & & & & & 641 & & \\
\hline P01-0-030 & P1 & 374 & & & & & 374 & & \\
\hline P01-0-035 & P1 & 700 & & & & & 700 & & \\
\hline P01-0-036 & P3 & 709 & 3.180 & & & & 3.889 & & \\
\hline P01-0-040 & P1 & 37.038 & 1.500 & 400 & & & 108.000 & 99.900 & $80 \%$ \\
\hline
\end{tabular}

Como já foi referido na Secção 1, não é relevante levar em consideração, neste processo de decisão, os custos afundados, pois já foram incorridos e são irrecuperáveis se a empresa interromper a atividade, mas somente os custos a incorrer no futuro. Os custos a incorrer correspondem à parcela do custo total de investimento a realizar no futuro. Naturalmente, a restante parcela corresponde ao investimento já realizado, que será necessariamente positivo para aquelas atividades que já se encontram em curso (pacote P1) e que para as quais já houve lugar ao pagamento de despesas (ver na Tabela 2, por exemplo, a atividade com o código P01-0-040). Os custos a incorrer com cada atividade foram também desagregados temporalmente por ano (2006, 2007, 2008 e anos seguintes) com base na calendarização prevista até à sua completa implementação.

Uma vez que o financiamento de algumas das atividades poderia vir a incluir uma comparticipação comunitária, analisou-se também a hipótese de considerar apenas como custo de investimento dessas atividades os custos a incorrer (caso esse cofinanciamento efetivamente ocorresse). Os custos a 
incorrer (com financiamento comunitário) foram calculados de acordo com a seguinte expressão:

$\underset{(\text { com financiamento })}{\text { Custos a incorrer }}=$ custos a incorrer $\times\left(\frac{\text { custo total }- \text { despesas elegíveis } \times \text { perc. de comparticipação }}{\text { custo total }}\right)$

A Tabela 3 apresenta os custos totais de investimento a incorrer (em euros) com a realização do total das atividades inscritas no Plano de acordo com os pacotes (apresentados na Tabela 1) e os setores (apresentados no início da Secção 3) a que se encontram afetos.

Tabela 3: Custos totais de investimento a incorrer por setor e pacote (em milhares de euros)

\begin{tabular}{lrrrrrrrr}
\hline Setor & P1 & P2 & P3 & P4 & P5 & P6 & P7 & Total \\
\hline S1 & 218.212 & & 30.904 & 18.000 & 5.900 & 84.841 & 276.040 & 633.897 \\
S2 & 5.936 & 118.248 & & 46.542 & & 14.095 & & 184.821 \\
S3 & 14.727 & 143.100 & 4.742 & 46.617 & 555 & 81 & & 209.821 \\
S4 & 25.108 & 5.058 & & & 29.738 & & & 59.903 \\
S5 & 13 & & & 1.114 & 126 & 40 & & 1.292 \\
S6 & 11.686 & & & 8.375 & & & 16.433 & 36.493 \\
S7 & 7.563 & & 1.500 & 3.562 & 51.480 & 30.500 & 63.455 & 158.060 \\
S8 & 13.341 & & & & 139.914 & & & 153.255 \\
S9 & 20.308 & 133.894 & & & & & 594.248 & 748.449 \\
S10 & & 68.504 & & 14.833 & & & & 83.338 \\
S11 & & & 76.438 & & & & & 76.438 \\
S12 & 6.808 & & & & 3.250 & & & 10.058 \\
S13 & 1.060 & & 0,5 & & 1.284 & & & 2.345 \\
S14 & 2.048 & & 488 & & 1.260 & & & 3.796 \\
S15 & 325 & & & & 95 & & & 420 \\
\hline Total & 327.133 & 468.804 & 114.072 & 139.043 & 233.602 & 129.557 & 950.175 & 2.362 .385 \\
\hline
\end{tabular}

É possível destacar o seguinte em relação a estes montantes: o custo a incorrer com a realização de todas as atividades inscritas no Plano soma cerca de 2,3 mil milhões de euros (embora esse montante baixe para 1,7 mil milhões de euros com o eventual cofinanciamento comunitário); apesar de cerca de metade das atividades ter sido classificada no pacote $\mathrm{P} 1$ relativo às atividades em curso e/ou indispensáveis (ver Tabela 1), este pacote corresponde apenas a 
cerca de 13\% do custo total; os custos das atividades inseridas no pacote P7 relativo às atividades importantes com prioridade de terceira ordem representam cerca de $40 \%$ do custo total; os setores S1 (Intervenção na Linha do Norte) e S9 (Ligação Porto de Sines - Espanha) representam por si só cerca de $60 \%$ do total dos custos de investimento a incorrer. Estes valores são bem demonstrativos do tipo de atividades em análise, com longos prazos até à sua implementação (nomeadamente a construção) e prazos ainda mais longos de exploração, o que reforçam a necessidade de se planear cuidadosamente a sua realização numa perspetiva de médio/longo prazo através de planos plurianuais.

\section{Identificação e estruturação dos objetivos estratégicos}

Esta etapa metodológica foi iniciada pelo DG, logo após a identificação dos atores-chave deste processo de decisão, convocando-os para uma conferência de decisão. A conferência de decisão iniciou-se com uma descrição das principais linhas de orientação do trabalho a realizar, das condicionantes existentes e da metodologia de apoio à decisão, quer do ponto de vista técnico como social, que iria apoiar esse processo com vista à produção dos resultados desejados.

Em contextos organizacionais com múltiplos atores que têm diferentes interesses, valores, preferências e agendas em jogo é natural que existam diversas perspetivas individuais acerca do problema em mãos, que deverão estar representadas no processo de análise de decisão (Russo e Schoemaker, 1989; Keeney, 2007) e que combinadas permitem obter uma perspetiva de grupo (Phillips, 1990). Por essa razão, os Decisores foram questionados relativamente ao objetivo global que a DGEN pretendia atingir com a realização das atividades propostas no Plano. A resposta consubstanciou-se através da definição explícita do objetivo global «investir eficientemente nos próximos anos na REFER, considerando o orçamento disponível da DGEN para 2006». A definição, de uma forma clara e partilhada, de um único objetivo global e perspetiva de avaliação, permitiu alinhar os diversos Decisores em direção a um objetivo comum durante todo o processo subsequente de elaboração do Plano. 
As atividades propostas no Plano visam naturalmente satisfazer diversos objetivos fundamentais da REFER. A sua identificação e estruturação deve especificar o objetivo global anteriormente estabelecido, com base numa abordagem centrada nos valores (Keeney, 1992). Recorrendo à construção de mapas cognitivos (Eden, 1988; Eden e Simpson, 1989), começou-se por indagar os Decisores acerca dos aspetos e preocupações que consideravam mais relevantes relativamente a este contexto de decisão. Para o efeito, através de um procedimento dinâmico de perguntas-respostas, os autores foram colocando questões aos Decisores do seguinte tipo: $O$ que consideram importante alcançar/atingir a médio e a longo prazo? Por que é que a realização de determinada atividade é importante/relevante? Como é que isso pode ser alcançado?. As respostas foram sendo introduzidas, em tempo real, no software Decision Explorer (Banxia, 2002), e projetadas num ecrã, resultando desse procedimento um mapa cognitivo (Figura 3) com conceitos interligados entre si por relações causa-efeito. Analisando o mapa cognitivo da Figura 3 podem encontrar-se várias cadeias de conceitos. Por exemplo, efetuar a «30 Supervisão técnica de infraestruturas» permite uma maior "14 Rapidez de intervenção», que possibilita aumentar a «15 Disponibilidade» da infraestrutura, que contribui para garantir a «16 Continuidade do serviço», que por sua vez é relevante para a satisfação do "6 Operador / Cliente final». Desta cadeia resultaram o objetivo fundamental «2.3. Garantir a continuidade do serviço» e a área de preocupação «2. Satisfação do operador/cliente final» referidos na estrutura arborescente de objetivos que se apresenta mais adiante.

Pela sua relevância destacam-se dois tipos de conceitos:

- Objetivos-fins: que resultam de respostas à pergunta «Por que é que esse aspeto é importante?»;

- Objetivos-meios: que resultam de respostas à pergunta "Como é que esse aspeto pode ser alcançado?».

Os objetivos-fins representam os objetivos fundamentais a atingir pela REFER (por exemplo, "3 Diminuir tempo de trajeto") e os objetivos-meios (como por exemplo, melhorar as "24 Telecomunicações») representam objetivos intermédios, meios ou atividades específicas necessários para atingir os objetivos-fins. 
Em simultâneo, de uma forma progressiva e resultante da interação entre os diversos Decisores, foi-se construindo e projetando num outro ecrã uma estrutura arborescente dos objetivos da REFER que, após algumas revisões, estabilizou na seguinte forma:

1. Fatores intrínsecos à REFER

1.1. Reduzir os custos de manutenção

1.2. Reduzir os custos de operação

1.3. Melhorar a eficiência da gestão

1.4. Evitar acidentes

1.4.1. Evitar acidentes pessoais

1.4.2. Evitar acidentes materiais

1.5. Garantir a segurança de pessoas e bens

2. Satisfação do operador/cliente final

2.1. Aumentar a utilização da infraestrutura

2.2. Reduzir o tempo de trajeto

2.3. Garantir a continuidade do serviço

2.4. Aumentar a atratividade do sistema

2.4.1. Passageiros

2.4.2. Mercadorias

3. Cumprimento das obrigações legais (nacionais e comunitárias)

3.1. Acessibilidade

3.2. Ruído

3.3. Intervenções artísticas

3.4. Passagens de nível

Os objetivos fundamentais estão representados no nível mais baixo da estrutura arborescente de objetivos. Os objetivos de nível superior representam áreas de preocupação que agrupam conjuntos de objetivos fundamentais. Os impactos e pontuações das atividades são determinados ao nível dos objetivos fundamentais (doravante designados simplesmente por objetivos).

Esta etapa de construção de uma forma partilhada dos objetivos estratégicos foi essencial, pois permitiu consolidar uma estrutura comum de avaliação e fundamentação dos benefícios das diversas atividades propostas, com base 
na qual se estabeleceu uma linguagem formal de comunicação entre os vários atores do processo.

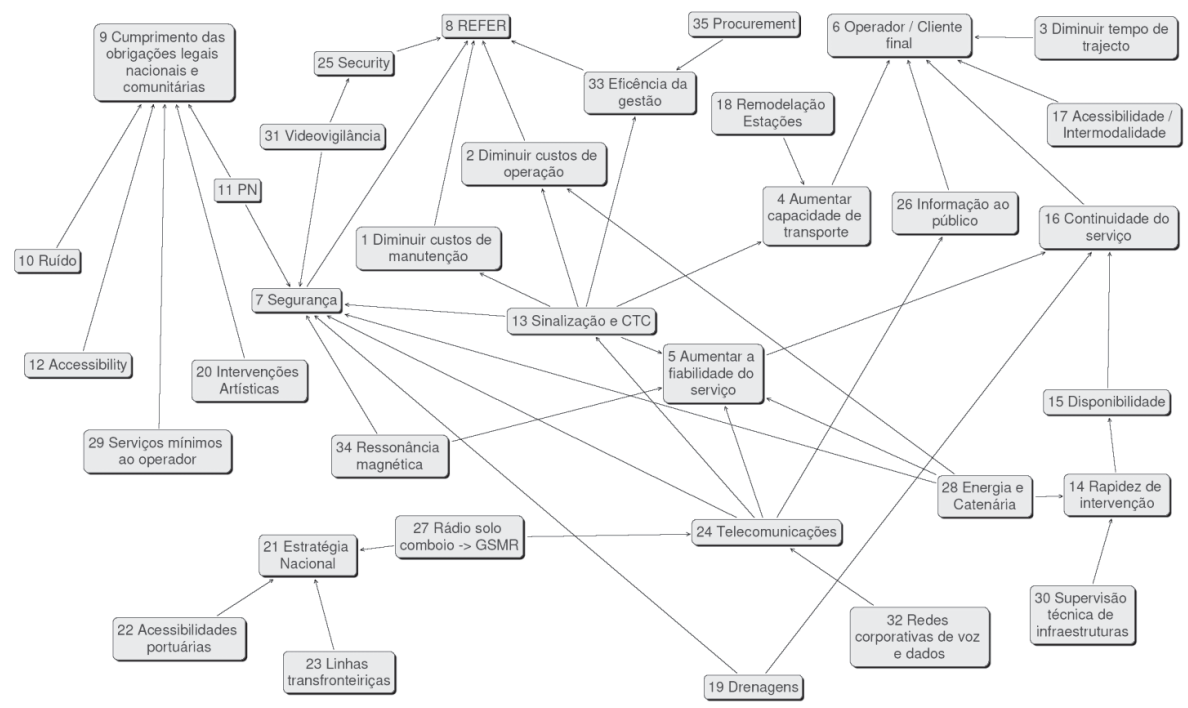

Figura 3: Mapa cognitivo

Existem vários modelos de agregação das preferências expressas em múltiplos objetivos. Neste caso, optou-se por utilizar o modelo aditivo simples de agregação com base na teoria de valor multicritério, onde a pontuação global de cada atividade é determinada pela soma dos produtos das pontuações parciais dessa atividade, segundo os diversos objetivos, pelos respetivos pesos, cuja expressão se mostra de seguida:

$$
B(a)=\sum_{o=1}^{n} k_{o} \times b_{o}\left(i_{o}(a)\right), \operatorname{com} \sum_{o=1}^{n} k_{o}=1 \text { e } 0<k_{o}<1
$$

em que,

- $\quad B(a)$ corresponde à pontuação global da atividade $a$, que representa o valor relativo do seu benefício global, tendo em consideração todos os objetivos fundamentais;

- $n$ corresponde ao número de objetivos fundamentais; 
- $i_{o}(a)$ corresponde ao impacto da atividade a segundo o objetivo $o$, obtido de acordo com um descritor de impactos $i_{o}($.$) ;$

- $\quad b_{o}\left(i_{o}(a)\right)$ corresponde à pontuação parcial do impacto da atividade $a$, segundo o objetivo $o$, que representa o valor do seu benefício parcial segundo esse objetivo;

- $\quad k_{o}$ corresponde ao peso do objetivo $o$.

Identificar objetivos e organizá-los numa estrutura arborescente não garante porém a coerência intrínseca do modelo de avaliação aditivo definido em (1). Para o efeito, é necessário garantir o cumprimento de algumas propriedades fundamentais e procurar desejavelmente o cumprimento de outras (Dogson et al., 2000; Keeney, 1992 e 2007). Por exemplo, tal como referido anteriormente, é essencial identificar os objetivos-fins de forma a não introduzir no modelo redundâncias que iriam sobrevalorizar impactos que só deveriam ser considerados uma única vez. É também essencial garantir que é possível avaliar cada atividade segundo cada um dos objetivos fundamentais sem levar em consideração o seu desempenho nos restantes (propriedade que é conhecida como «independência preferencial» (Dyer e Sarin, 1979)). Outras propriedades importantes incluem a verificação da exaustividade, concisão (parcimónia), consensualidade, operacionalidade e inteligibilidade (não-ambiguidade). As três primeiras podem ser alcançadas através da sua estruturação com base em abordagens partilhadas e construtivas tais como as realizadas neste caso através dos mapas cognitivos. Já as duas últimas podem ser sobretudo garantidas através da definição de adequados descritores de impactos, tal como se descreve na próxima secção.

Outra vantagem adicional deste tipo de estrutura advém da possibilidade de os diversos órgãos da DGEN poderem identificar novas oportunidades de decisão com base num questionamento sobre quais as melhores formas de melhorar os objetivos fundamentais identificados. Desta forma é possível identificar novas atividades e justificar desde logo os seus eventuais benefícios. Se uma nova atividade não contribui para atingir ou melhorar pelo menos um objetivo, é porque ou não têm razão de ser ou então é necessário rever a estrutura de objetivos fundamentais anteriormente definida. 


\section{Definição de descritores de impactos}

A determinação dos benefícios gerados pela realização das atividades exige que seja definida uma forma (quantitativa ou qualitativa) de medir ou estimar os seus impactos segundo cada um dos objetivos fundamentais identificados na fase anterior. Um descritor de impactos é um conjunto de níveis de impacto concretos ordenado por ordem de preferência segundo um determinado objetivo fundamental. O significado de um objetivo fundamental é descrito de uma forma clara e objetiva pelo seu descritor de impactos. Cada objetivo fundamental é operacionalizado por um e um só descritor de impactos. Um descritor de impactos serve assim para medir a contribuição de cada atividade para a consecução de um determinado objetivo fundamental.

As atividades propostas no Plano vão agir sobre uma realidade pré-existente. Há vantagens significativas em medir, estimar ou avaliar os impactos destas atividades em relação a uma situação base ou de referência (baseline) (Clemen e Smith, 2009), quer ela corresponda à situação atual (status quo) (Bana e Costa et al., 2014), à situação de manutenção da tendência atual (business as usual) (Neves et al., 2012) ou outra. São duas as vantagens inerentes à utilização dessa linha de referência: a primeira é a de permitir comparar o mérito de cada atividade em relação à situação de referência sem ter de determinar os seus impactos, possibilitando assim uma avaliação relativa das atividades em relação a essa situação de referência; a segunda é a de reduzir o esforço inerente à determinação dos impactos das atividades, uma vez que é normalmente mais fácil medir apenas o impacto (acrescido) da realização de uma determinada atividade (por exemplo, +1.000 passageiros/ano em relação ao status quo) do que medir o desempenho que resulta no sistema em análise

após a realização dessa atividade (por exemplo, 5,1 milhões de passageiros/ano, resultantes dos 5 milhões de passageiros/ano do status quo mais os 1.000 passageiros/ano da atividade).

A definição dos descritores de impactos foi desenvolvida em colaboração com os técnicos da REFER e alguns dos Decisores da DGEN, sob a supervisão do DG. Existiu sempre a preocupação de identificar descritores naturais. Quando não foi possível usar um descritor deste tipo, por exemplo, devido a dificuldades em obter a informação necessária para quantificar os impactos de 
todas as atividades, definiu-se em alternativa um descritor indireto quantitativo. Só quando não foi possível definir um descritor quantitativo (direto ou indireto), é que se optou por definir um descritor qualitativo construído.

A Tabela 4 apresenta uma descrição abreviada dos descritores de impactos definidos para os objetivos fundamentais identificados na fase anterior.

A responsabilidade pela determinação dos impactos das atividades, de acordo com o descritor definido para cada objetivo, foi distribuída ao nível dos diversos órgãos e técnicos especialistas da REFER em função do seu grau de atribuições, competências e responsabilidades dentro da estrutura organizacional da empresa (Tabela 4). Note-se que a informação necessária para a determinação dos impactos segundo a maioria dos objetivos existia em Direções fora da esfera de influência da DGEN, tais como a DEx, a DC, a S, o A e o PE (ver Figura 1). A responsabilidade pela determinação dos respetivos impactos foi assim atribuída a esses órgãos (este grupo juntamente com os Decisores serão doravante designados simplesmente por Representantes da REFER).

Esta fase de estruturação dos descritores seguiu igualmente um processo iterativo e recursivo de aprendizagem, de que resultaram algumas alterações, inclusive em relação à estrutura inicial de objetivos estratégicos fundamentais.

\section{Estimação dos impactos das atividades}

Uma importante convicção metodológica desta metodologia de apoio à decisão reside na «interrelação e inseparabilidade entre os elementos objetivos e subjetivos do contexto de decisão" (Bana e Costa, 1993b). A estimativa dos impactos é o resultado de um sistema de relações entre elementos de natureza objetiva e elementos de natureza subjetiva. Estes dois elementos são indissociáveis e nenhum deles deve ser negligenciado. A procura da objetividade deve ser uma preocupação presente, mas convém não esquecer que a subjetividade está sempre omnipresente nas decisões (é fundamental não esquecer que a tomada de decisão é antes do mais uma atividade humana) e, portanto, é essencial incorporar todo o conhecimento, não apenas os elementos de natureza objetiva mas também, de uma forma estruturada e 
Tabela 4: Objetivos fundamentais e descritores de impacto

\begin{tabular}{|c|c|c|}
\hline \multicolumn{2}{|c|}{ Objetivos } & Descritor de Impactos \\
\hline 1 & \multicolumn{2}{|c|}{ Fatores intrínsecos à REFER } \\
\hline 1.1 & $\begin{array}{l}\text { Reduzir os custos de } \\
\text { manutenção }\end{array}$ & 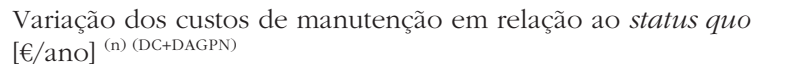 \\
\hline 1.2 & $\begin{array}{l}\text { Reduzir os custos de } \\
\text { operação }\end{array}$ & $\begin{array}{l}\text { Variação dos custos de operação em relação ao status quo } \\
\text { [€/ano] }^{(\text {n) (DEx+DAGPN) }}\end{array}$ \\
\hline 1.3 & $\begin{array}{l}\text { Melhorar a eficiência } \\
\text { da gestão }\end{array}$ & $\begin{array}{l}\text { Conjunto ordenado de níveis qualitativos descrevendo impactos } \\
\text { plausíveis distintos em termos do objetivo (c) (DG) }\end{array}$ \\
\hline 1.4 .1 & $\begin{array}{l}\text { Evitar acidentes } \\
\text { pessoais }\end{array}$ & $\begin{array}{l}\text { Variação do } n .{ }^{\circ} \text { de acidentes pessoais em relação ao status quo } \\
\text { [n. }^{\circ} \text { de mortos equivalentes }{ }^{1} / \text { ano] }^{(\mathrm{n})(\mathrm{S}+\mathrm{DAGPN})}\end{array}$ \\
\hline 1.4 .2 & $\begin{array}{l}\text { Evitar acidentes } \\
\text { materiais }\end{array}$ & $\begin{array}{l}\text { Variação do } \text {. }^{\circ} \text { de acidentes sobre materiais sob a } \\
\text { responsabilidade da REFER em relação ao status quo [n. }{ }^{\circ} \text { de } \\
\text { acidentes materiais/ano] }{ }^{\text {(p) } 2 \text { (DC+DAGPN) }}\end{array}$ \\
\hline 1.5 & $\begin{array}{l}\text { Garantir a segurança } \\
\text { de pessoas e bens }\end{array}$ & $\begin{array}{l}\text { Variação do } \text {. }^{\circ} \text { de atos de vandalismo sobre pessoas }{ }^{3} \text { ou bens }{ }^{4} \text { sob a } \\
\text { responsabilidade da REFER em relação ao status quo [\%/ano] }{ }^{(\mathrm{p})} 5(\mathrm{~s})\end{array}$ \\
\hline 2 & \multicolumn{2}{|c|}{ Satisfação do operador ferroviário/cliente final } \\
\hline 2.1 & $\begin{array}{l}\text { Aumentar a utilização } \\
\text { da infraestrutura }\end{array}$ & $\begin{array}{l}\text { Aumento da capacidade de transporte em novas linhas ou } \\
\text { linhas congestionadas em relação ao status quo } \\
\text { [comboios.km/ano] }^{(\mathrm{p})} 6 \text { (DEx) }\end{array}$ \\
\hline 2.2 & $\begin{array}{l}\text { Reduzir o tempo de } \\
\text { trajeto }\end{array}$ & $\begin{array}{l}\text { Variação do total das poupanças de tempo de trajeto }{ }^{7} \mathrm{em} \\
\text { relação ao status quo [comboios.minutos/ano] }{ }^{(\mathrm{n})(\mathrm{DEx})}\end{array}$ \\
\hline 2.3 & $\begin{array}{l}\text { Garantir a } \\
\text { continuidade do }\end{array}$ & $\begin{array}{l}\text { Variação do total dos atrasos }{ }^{8} \text { por causas imputáveis à REFER } \\
\text { em relação ao status quo [comboios.minutos/ano] }{ }^{(n)(\mathrm{DEx}+\mathrm{DC})}\end{array}$ \\
\hline
\end{tabular}

2.4.1 Aumentar a Variação da utilização do sistema ferroviário por passageiros em atratividade do sistema relação ao status quo [passageiros/ano] ${ }^{(\mathrm{n})(\mathrm{PE})}$ (passageiros)

2.4.2 Aumentar a Variação da utilização do sistema ferroviário por mercadorias atratividade do sistema em relação ao status quo [toneladas/ano] ${ }^{(\mathrm{n})(\mathrm{PE})}$ (mercadorias)

3 Cumprimento das obrigações legais (nacionais e comunitárias)

3.1 Acessibilidade $\quad$ Variação do n. ${ }^{\circ}$ de estações com acessibilidade a deficientes em relação ao status quo [n. $^{\circ}$ de estações] ${ }^{(n)(D I)}$

3.2 Ruído $\quad$ Variação do . $^{\circ}$ de pessoas beneficiadas por medidas de proteção de ruído nos grandes eixos ferroviários em relação ao status quo $\left[\mathrm{n}^{\circ}{ }^{\circ}\right.$ de pessoas] ${ }^{(\mathrm{p})(\mathrm{A})}$

3.3 Intervenções Artísticas Variação do n. ${ }^{\circ}$ de estações em incumprimento da legislação referente a intervenções artísticas em relação ao status quo [n. ${ }^{\circ}$ de estações] ${ }^{(n)(D G)}$

3.4 Passagens de Nível Variação do n. ${ }^{\circ}$ de passagens de nível em incumprimento da respetiva legislação em relação ao status quo [n. ${ }^{\circ}$ de passagens de nível] ${ }^{(n) \text { (DAGPN) }}$

Legenda: ${ }^{(\mathrm{n})}$ descritor natural; ${ }^{(\mathrm{p})}$ descritor indireto; ${ }^{\left({ }^{(}\right)}$descritor qualitativo construído

\footnotetext{
${ }^{1}$ Mortos equivalentes $=$ mortos + feridos graves $/ 10+$ feridos ligeiros $/ 200$

${ }^{2}$ Descritor natural quantitativo: variação dos prejuízos (em €/ano) causados por acidentes materiais, da responsabilidade da REFER (sobre a infraestrutura, material circulante, etc.), em relação ao status quo

${ }^{3}$ Exemplos: assaltos e atos de violência física

${ }^{4}$ Exemplos: furtos ou destruição de equipamento ferroviário, danos na infraestrutura, etc.

${ }^{5}$ Descritores naturais quantitativos: variação do $\mathrm{n} .{ }^{\circ}$ de atos de vandalismo sobre as pessoas (em n. ${ }^{\circ}$ de atos de vandalismo/ano), nas estações sob a responsabilidade da REFER, em relação ao status quo; variação dos prejuízos (em €/ano) causados por atos de vandalismo sobre bens, da responsabilidade da REFER, em relação ao status quo

${ }^{6}$ Descritor natural quantitativo: variação da utilização da infraestrutura (em comboios.km/ano) em relação ao status quo

${ }^{7}$ Nos trajetos onde não estão previstos investimentos em linhas de Alta Velocidade

${ }^{8}$ Diretos, indiretos e considerados (em que o atraso máximo equivalente a uma supressão de comboio é igual a 1 hora)
} 
rigorosa, todos os elementos subjetivos (experiência, conhecimentos, convicções, juízos de valor) de natureza qualitativa na posse dos técnicos da REFER.

Considerando que a estimativa da ocorrência de qualquer acontecimento futuro é por natureza incerta, a estimativa dos impactos das atividades não pode deixar de possuir uma componente de risco e incerteza. Esta componente foi incorporada da seguinte forma:

- por um lado, os impactos das atividades foram estimados através de um único valor (melhor estimativa do impacto) e/ou através de um intervalo plausível (sendo neste caso, à semelhança do que foi feito para os custos, posteriormente utilizado o ponto médio desse intervalo como estimativa desse impacto);

- por outro lado, sempre que o valor do impacto de uma atividade compreendia uma série de estimativas de impacto juntamente com as suas probabilidades de ocorrência, o valor esperado do impacto foi estimado através da soma ponderada desses fatores (Clemen, 1996).

A título de exemplo, refira-se como os impactos das atividades relativas à supressão de passagens de nível no objetivo «1.4.2 Evitar acidentes materiais» foram determinados: analisou-se o histórico dos últimos cinco anos do número de acidentes materiais, da responsabilidade da REFER, que ocorreram nas respetivas passagens de nível; ao limite inferior plausível foi atribuído o menor número de acidentes materiais anual, ao limite superior plausível correspondeu o maior número de acidentes materiais anual e o valor esperado desse impacto foi determinado com base na média dos acidentes materiais desses últimos cinco anos (ou seja, considerando que a probabilidade de ocorrência de cada acidente material anual se mantém igual ao longo dos anos). O resultado final desta etapa metodológica foi consolidado numa matriz com os impactos de cada atividade (em linha) segundo cada um dos objetivos (em coluna), tal como se ilustra na Tabela 5 para algumas atividades representativas do Plano.

Cada atividade pode ter impactos em vários objetivos, mas nem todos esses impactos são obrigatoriamente positivos. Por exemplo, algumas atividades (P01-0-190 e P03-3-005) podem ter impactos positivos em objetivos tais como 
"1.4.1 Evitar acidentes pessoais» ou "2.3 Garantir a continuidade do serviço», que consequentemente impliquem impactos negativos em relação a outros objetivos como é o caso do objetivo "1.1 Reduzir os custos de manutenção». Repare-se também que não foram estimados quaisquer impactos para a atividade P01-0-080, relativa à elaboração do projeto de execução da Estação do Entroncamento, uma vez que esses impactos só se materializarão após a realização da respetiva Estação (atividade P01-0-081).

Tabela 5: Impactos estimados das atividades

\begin{tabular}{|c|c|c|c|c|c|c|c|c|c|c|c|c|c|c|c|}
\hline Código & 1.1 & 1.2 & 1.3 & 1.4 .1 & 1.4 .2 & 1.5 & 2.1 & 2.2 & 2.3 & 2.4 .1 & 2.4 .2 & 3.1 & 3.23 & 3.3 & 3.4 \\
\hline P01-0-015 & $-0,5$ & & & & $-1,8$ & & & & & & & & & & \\
\hline P01-0-036 & & & & $-0,17$ & -1 & & & & & & & & & & \\
\hline P01-0-075 & $-0,6$ & $-0,1$ & & $-0,01$ & $-2,4$ & & & & -47 & 80 & 180 & 2 & 0,1 & & \\
\hline \multicolumn{16}{|l|}{ P01-0-080 } \\
\hline P01-0-081 & $-0,5$ & $-0,9$ & & $-0,06$ & $-15,2$ & & & & -7 & & & 1 & & & \\
\hline P01-0-190 & 0,1 & $-1,4$ & & $-2,76$ & $-18,8$ & & & & -58 & 551 & 180 & 14 & 4,1 & & \\
\hline P02-0-080 & $-0,2$ & $-0,1$ & & $-0,4$ & $-1,8$ & & & 68 & $-0,7$ & 8 & 68 & 5 & & & \\
\hline P03-3-005 & 1,4 & & & & $-0,20$ & & & 7 & $-0,3$ & 100 & & & & & \\
\hline P05-0-040 & & & & & & & & & & & & & & -1 & \\
\hline P08-0-025 & & & & $-0,69$ & $-3,2$ & & 482 & 16 & & 205 & & 1 & 2,3 & & \\
\hline P13-0-010 & $-0,2$ & $-0,2$ & & -6 & $-16,2$ & & & & & & & & & & -80 \\
\hline P13-21-010 & & & & & & -25 & & & & 175 & & & & & \\
\hline P16-34-020 & & & $\mathrm{N} 2$ & & & & & & & & & & & & \\
\hline
\end{tabular}

Unidades: 1.1 e 1.2 em milhões euros/ano; 2.1 em milhares de comboios.km/ano; 2.2 e 2.3 em milhares de comboios.minutos/ano; $2.4 .1 \mathrm{em}$ milhares de passageiros/ano; $2.4 .2 \mathrm{em}$ milhares de toneladas/ano; $3.2 \mathrm{em}$ milhares de pessoas

Os impactos das atividades foram validados numa reunião conjunta com os Representantes da REFER. Uma técnica que auxiliou bastante este trabalho foi a de ordenar previamente todas as atividades por ordem decrescente dos seus impactos segundo cada um dos objetivos, tal como se apresenta, na Tabela 6, para o objetivo «2.3 Garantir a continuidade do serviço».

Os impactos das atividades segundo o objetivo «1.3 Melhorar a eficiência da gestão» foram determinados de forma distinta. Numa primeira fase, analisou-se o impacto previsto de cada atividade no objetivo em causa. Posteriormente, os 
impactos foram classificados segundo um conjunto de níveis distintos ordenados por ordem decrescente de preferência (ver Tabela 7).

Tabela 6: Impactos por ordem decrescente segundo o objetivo 2.3

\begin{tabular}{llr}
\hline Código & Atividade & $\Delta$ atrasos \\
\hline P01-0-140 & Modernização Alfarelos/Pampilhosa & -82.631 \\
P01-0-190 & Modernização Ovar/Gaia & -57.936 \\
P01-0-075 & Modernização Mato Miranda/Entroncamento & -46.541 \\
P01-0-065 & Modernização Vale de Santarém/Mato Miranda - Variante de Santarém & -29.619 \\
P04-0-045 & Troço Alfarelos - Louriçal - Figueira da Foz & -24.607 \\
P02-0-020 & Subst. Armamento de via, Piquetagem e Remodelação de 5 estações e & -10.680 \\
& Apeadeiros & -7.306 \\
P01-0-081 & Estação do Entroncamento & -6.384 \\
P02-0-055 & C. Civil, Via e Catenária, RCT+TP, Sinalização, Telecomunicações, & -3.052 \\
P09-0-020 & Telecomando Catenária, RSC, Convel, SST Fatela & -655 \\
P02-0-080 & C. Civil, Via e Catenária, RCT+TP, Sinalização, Telecomunicações, & -280 \\
P03-3-005 & Telecomando Catenária, RSC, Convel & Cariante de Alcácer \\
\hline & &
\end{tabular}

A realização em conjunto de algumas atividades pode gerar impactos superiores (ou inferiores) à soma dos respetivos impactos individuais, pelo que é fundamental identificar e modelar as sinergias (ou antagonismos) existentes entre atividades. Por exemplo, durante a determinação dos impactos de algumas atividades, segundo o objetivo "2.1 Aumentar a utilização da infraestrutura», verificou-se que a ordem com que cada atividade era realizada tinha como efeito impactos diferentes.

Os impactos destas atividades foram assim ajustados com base na sequencialidade da sua realização. A Tabela 8 exemplifica um desses casos. A atividade P08-0-025 quando realizada em conjunto com a atividade P08-0-022 tinha um impacto estimado de 429.687 passageiros/ano. Como a segunda atividade está incluída no pacote P6 realizar-se-á sempre depois da primeira (que está incluída no pacote P5). Consequentemente, o impacto da segunda atividade foi ajustado de forma a incluir apenas o impacto acrescentado por esta atividade. Um procedimento semelhante foi realizado para a atividade P07$2-010$. 
Tabela 7: Níveis de impactos segundo o objetivo 1.3

\begin{tabular}{|c|c|c|c|}
\hline Código & Atividade & Impacto & Nível \\
\hline P16-34-010 & $\begin{array}{l}\text { Implementação de um sistema de } \\
\text { Gestão de Qualidade }\end{array}$ & $\begin{array}{l}\text { Diminuição dos custos da não- } \\
\text { qualidade (tempos, custos, } \\
\text { performance, riscos) }\end{array}$ & N1 \\
\hline P14-28-004 & $\begin{array}{l}\text { Implementação de um Sistema de } \\
\text { Qualificação de Empreiteiros }\end{array}$ & $\begin{array}{l}\text { Redução dos prazos de concursos e } \\
\text { consultas para empreitadas, } \\
\text { garantia acrescida de boa execução } \\
\text { e avaliação contínua de } \\
\text { desempenho }\end{array}$ & $\mathrm{N} 2$ \\
\hline P14-28-005 & $\begin{array}{l}\text { Implementação de um Sistema de } \\
\text { Qualificação de Prestadores de } \\
\text { Serviço de Fiscalização }\end{array}$ & $\begin{array}{l}\text { Redução dos prazos de concursos e } \\
\text { consultas para fiscalizações, } \\
\text { garantia acrescida de boa execução } \\
\text { e avaliação contínua de } \\
\text { desempenho }\end{array}$ & $\mathrm{N} 2$ \\
\hline P16-34-020 & $\begin{array}{l}\text { Integração do Planeamento da } \\
\text { DGEN em SAP/R3 }\end{array}$ & $\begin{array}{l}\text { Melhor gestão dos recursos } \\
\text { financeiros }\end{array}$ & $\mathrm{N} 2$ \\
\hline P14-28-006 & $\begin{array}{l}\text { Assessoria para melhoria do } \\
\text { desempenho recorrendo ao } \\
\text { conceito RCM } 2\end{array}$ & $\begin{array}{l}\text { Interligação atividades entre } \\
\text { Engenharia e } \\
\text { Conservação/Manutenção }\end{array}$ & N3 \\
\hline P14-30-006 & $\begin{array}{l}\text { Gestão documental - Indexação e } \\
\text { digitalização de Desenhos Técnicos } \\
\text { da DGEN }\end{array}$ & $\begin{array}{l}\text { Facilidade no acesso à informação } \\
\text { técnica da infraestrutura ferroviária }\end{array}$ & N3 \\
\hline P14-28-001 & $\begin{array}{l}\text { Novos equipamentos / Sistemas } \\
\text { (GRP } 3000 \text {, GPS e de software para } \\
\text { projeto) }\end{array}$ & Melhorar o rigor dos projetos & N4 \\
\hline P14-28-003 & $\begin{array}{l}\text { Software do âmbito ferroviário } \\
\text { (projeto de terraplenagem e } \\
\text { drenagem) }\end{array}$ & Melhorar o rigor dos projetos & N4 \\
\hline P14-28-002 & $\begin{array}{l}\text { Projeto piloto de RFID } \\
\text { (identificação por rádio frequência) } \\
\text { nos AMVs }\end{array}$ & Melhorar a gestão de peças & N4 \\
\hline P14-30-007 & $\begin{array}{l}\text { Gestão documental - Custódia de } \\
\text { documentação e tratamento } \\
\text { documental arquivistico }\end{array}$ & $\begin{array}{l}\text { Transferir para terceiros a gestão e } \\
\text { custódia de documentação de } \\
\text { reduzida consulta }\end{array}$ & N5 \\
\hline P13-23-010 & Rede de Voz e Dados & $\begin{array}{l}\text { Ligações de dados (aplicações } \\
\text { informáticas de gestão / SAP, email, } \\
\text { intranet) e ligações de vOz (rede } \\
\text { telefónica automática) }\end{array}$ & N6 \\
\hline
\end{tabular}

Tabela 8: Impactos das atividades segundo o objetivo 2.1

\begin{tabular}{|c|c|c|c|}
\hline Código & Atividade & Pacote & Passageiros/ano \\
\hline P07-2-010 & $\begin{array}{l}\text { Quadruplicação Linha Cintura entre Chelas-B. Prata } \\
\text { (estações de passageiros) }\end{array}$ & P7 & 22.116 .650 \\
\hline P08-0-022 & $\begin{array}{l}\text { Remodelação estações passageiros Tercena Barcarena, } \\
\text { Quadruplicação }\end{array}$ & P6 & 225.156 \\
\hline P08-0-025 & Remodelação da Estação Cacém; Quadruplicação & P5 & 204.531 \\
\hline
\end{tabular}




\section{Avaliação dos benefícios parciais das atividades}

Os benefícios parciais de cada atividade, segundo cada objetivo, foram avaliados com base em funções de valor. Uma função de valor transforma cada nível de impacto plausível de um descritor num único valor numérico que representa o valor (ou atratividade) desse impacto segundo o objetivo em questão. As funções de valor permitem transformar impactos estimados em escalas de medição muito diferentes (por exemplo, €/ano, passageiros/ano, toneladas/ano, comboios.minuto/ano) em escalas cardinais (numéricas) que representam esses impactos em unidades de valor (pontuações) nos objetivos em questão. Existem vários métodos que permitem construir funções de valor (Goodwin e Wright, 2004; von Winterfeldt e Edwards, 1986; Bana e Costa e Vansnick, 1994). Qualquer que seja o método escolhido, um decisor deve começar por estabelecer a priori, segundo cada descritor, as pontuações associadas a dois níveis de impacto de referência distintos, atribuindo ao impacto mais atrativo uma pontuação superior à do impacto menos atrativo. Caso os níveis de impacto escolhidos possuam um valor intrínseco (correspondendo, por exemplo, a um nível considerado «bom» - i.e. muito positivo - ou "neutro» - i.e. nem positivo nem negativo), os impactos poderão ser avaliados de forma absoluta, permitindo tirar conclusões sobre se uma atividade é boa, muito boa, ou má (Bana e Costa, 1992a; Bana e Costa et al., 2000). Caso esses níveis de impacto de referência sejam de valor relativo, então apenas se pode concluir que uma determinada atividade é melhor, pior ou indiferente a outra, mas nada se pode concluir relativamente ao seu mérito absoluto. No caso aqui apresentado, os impactos de referência adotados em cada descritor foram o "melhor» impacto e o «status quo», respetivamente com 100 e 0 unidades de valor.

Para os objetivos com descritores quantitativos os Decisores optaram por funções de valor lineares. O pressuposto da linearidade dessas funções foi validado, para cada objetivo, com base em questões colocadas diretamente aos atores-chave da REFER relativamente às diferenças de atratividade (preferência) entre incrementos de igual dimensão na unidade do descritor (Goodwin e Wright, 2004). Por exemplo, relativamente ao objetivo «2.4.2 Aumentar a atratividade do sistema (mercadorias)», os Decisores consideraram que o valor 
do incremento de 0 toneladas/ano para 1 milhão de toneladas/ano era equivalente ao valor do incremento de 1 milhão de toneladas/ano para 2 milhões de toneladas/ano (ver Figura 4).

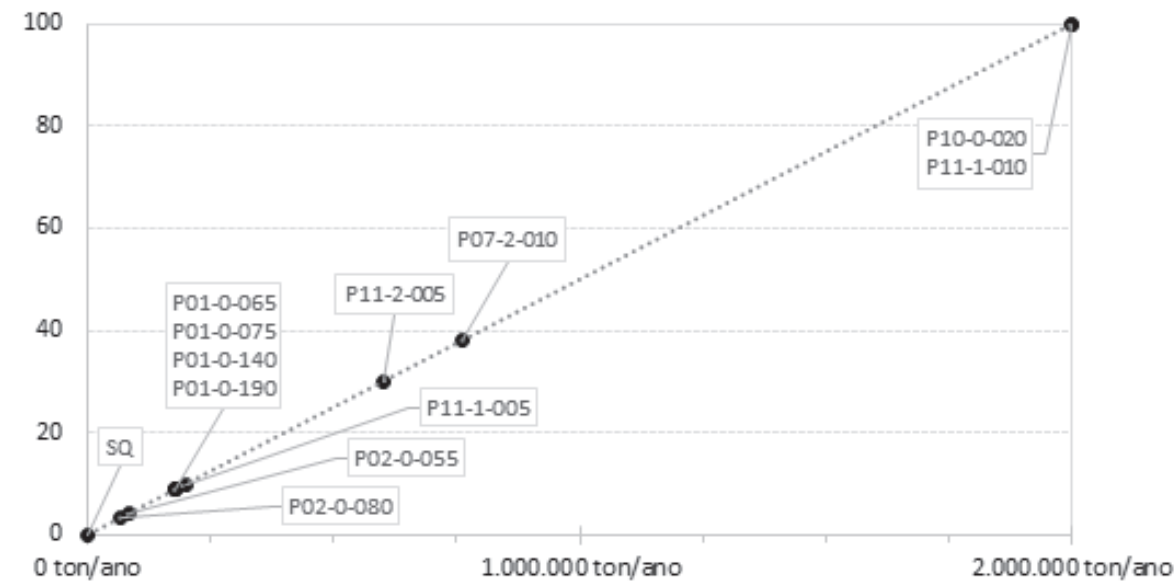

Figura 4: Função de valor linear do objetivo 2.4 .2

A função de valor referente ao objetivo "1.3 Melhorar a eficiência da gestão" foi construída com base no método MACBETH (Bana e Costa et al., 2012) e respetivo sistema de apoio à decisão M-MACBETH (Bana e Costa et al., 2005). As vantagens desta solução em relação a outras incluem: a possibilidade de construir escalas de valor, segundo um determinado objetivo, com base apenas em juízos qualitativos; a deteção automática de inconsistências entre as respostas dos decisores; e a sólida base científica em que se baseia, nomeadamente a definição de valor sobre uma escala de intervalos. Para além disso, os autores têm utilizado com sucesso o método em diversos contextos de decisão (Oliveira e Lourenço, 2002; Mateus et al., 2008; Bana e Costa et al., 2008).

Este método começa por questionar as preferências de um decisor em relação às diferenças de atratividade entre os vários níveis de impacto de um descritor, utilizando para o efeito uma escala semântica com sete categorias 
distintas de juízos de valor: nula; muito fraca; fraca; moderada; forte; muito forte; e extrema.

No caso presente, coube ao DG, como responsável pela determinação dos impactos bem como da realização das atividades, segundo este objetivo, a formulação do juízo qualitativo que no seu entender melhor representava a diferença de atratividade entre cada par de níveis de impacto do descritor associado ao objetivo 1.3 (ver Tabela 9). Esses juízos de valor são apresentados na matriz da Figura 5. Com base nesses juízos e na restrição de que ao melhor nível de impacto (N1) devem corresponder 100 unidades de valor e 0 unidades de valor ao status quo, o método MACBETH propõe uma escala de valor, atribuindo pontuações aos restantes níveis de impacto (ver coluna «Escala atual» da matriz apresentada na Figura 5).

Tabela 9: Níveis de impacto e pontuações parciais das atividades segundo o objetivo 1.3

\begin{tabular}{|c|c|c|c|}
\hline Código & Atividade & Impacto & Pontuação \\
\hline P16-34-010 & Implementação de um sistema de gestão de qualidade & N1 & 100 \\
\hline P14-28-004 & $\begin{array}{l}\text { Implementação de um sistema de qualificação de } \\
\text { empreiteiros }\end{array}$ & N2 & 87 \\
\hline P14-28-005 & $\begin{array}{l}\text { Implementação de um sistema de qualificação de } \\
\text { empresas de fiscalização }\end{array}$ & N2 & 87 \\
\hline P16-34-020 & Integração do planeamento da DGEN em SAP/R3 & N2 & 87 \\
\hline P14-28-006 & $\begin{array}{l}\text { Assessoria para melhoria do desempenho recorrendo ao } \\
\text { conceito RCM } 2\end{array}$ & N3 & 74 \\
\hline P14-30-006 & $\begin{array}{l}\text { Gestão documental: Indexação e digitalização de } \\
\text { desenhos técnicos da DGEN }\end{array}$ & N3 & 74 \\
\hline P14-28-001 & $\begin{array}{l}\text { Novos equipamentos/sistemas (GRP 3000, GPS e de } \\
\text { software para projeto). }\end{array}$ & N4 & 61 \\
\hline P14-28-003 & $\begin{array}{l}\text { Software do âmbito ferroviário (projeto de terraplenagem } \\
\text { e drenagem). }\end{array}$ & N4 & 61 \\
\hline P14-28-002 & $\begin{array}{l}\text { Projeto piloto de RFID (identificação por rádio frequência) } \\
\text { nos AMVs }\end{array}$ & N4 & 61 \\
\hline P14-30-007 & $\begin{array}{l}\text { Gestão documental: Custódia de documentação e } \\
\text { tratamento arquivístico }\end{array}$ & N5 & 43 \\
\hline P13-23-010 & Rede de voz e dados & N6 & 26 \\
\hline SQ & Status quo & SQ & 0 \\
\hline
\end{tabular}




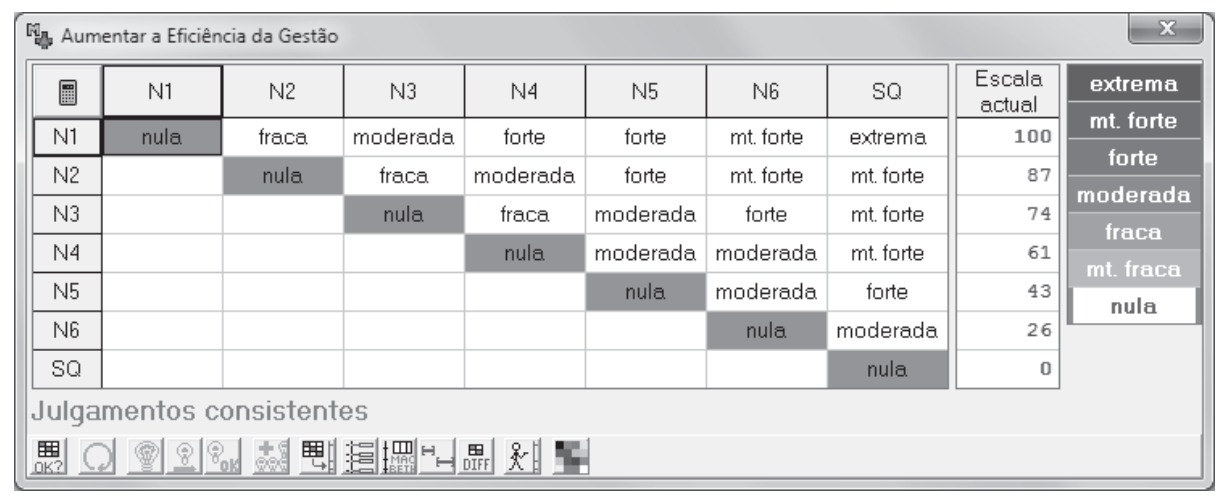

Figura 5: Matriz MACBETH e pontuações parciais segundo o objetivo 1.3

O resultado final desta etapa metodológica foi consolidado numa matriz com as pontuações parciais de cada atividade (em linha) segundo cada um dos objetivos (coluna), tal como se ilustra na Tabela 10 para algumas atividades do Plano. Estas pontuações resultam da aplicação das funções de valor definidas para cada um dos objetivos à matriz dos impactos das atividades desenvolvida e apresentada como resultado da etapa anterior (ver Tabela 5).

Tabela 10: Pontuações parciais das atividades segundo os objetivos fundamentais

\begin{tabular}{|c|c|c|c|c|c|c|c|c|c|c|c|c|c|c|}
\hline \multirow[b]{2}{*}{ Código } & \multicolumn{14}{|c|}{ Objetivos fundamentais } \\
\hline & 1.1 & 1.2 & 1.3 & 1.4 .1 & 1.4 .2 & 1.5 & 2.1 & 2.2 & 2.3 & 2.4 .1 & 2.4 .2 & 3.1 & 3.23 .3 & 33.4 \\
\hline P01-0-015 & 33,3 & & & & 2,6 & & & & & & & & & \\
\hline P01-0-036 & & & & 2,8 & 1,4 & & & & & & & & & \\
\hline P01-0-075 & 39,5 & 5,6 & & 0,1 & 3,4 & & & & 56,3 & 0,4 & 9,0 & 14,3 & 1,3 & \\
\hline P01-0-080 & & & & & & & & & & & & & & \\
\hline P01-0-081 & 34,0 & 60,6 & & 1,1 & 21,7 & & & & 8,8 & & & 7,1 & & \\
\hline P01-0-190 & $-6,9$ & 90,0 & & 46,0 & 26,9 & & & & 70,1 & 2,5 & 9,0 & 100 & 55,4 & \\
\hline P02-0-080 & 13,0 & 3,7 & & 6,7 & 2,6 & & & 100 & 0,8 & 0,1 & 3,4 & 35,7 & & \\
\hline P03-3-005 & $-96,3$ & & & & 0,3 & & & 10,7 & 0,3 & 0,5 & & & & \\
\hline P05-0-040 & & & & & & & & & & & & & 50 & \\
\hline P08-0-025 & & & & 11,4 & 4,6 & & 100 & 23,7 & & 0,9 & & 7,1 & 31,0 & \\
\hline P13-0-010 & 11,6 & 10,7 & & 100 & 23,1 & & & & & & & & & 100 \\
\hline P13-21-010 & & & & & & 100 & & & & 0,8 & & & & \\
\hline P16-34-020 & & & 87 & & & & & & & & & & & \\
\hline
\end{tabular}




\section{Ponderação dos objetivos}

A avaliação dos benefícios parciais das atividades permite retirar conclusões acerca da atratividade das atividades segundo cada objetivo, mas não permite avaliar a atratividade global dessas atividades.

Observe-se que no modelo de agregação aditivo definido em (1), os pesos dos objetivos não são mais que coeficientes de harmonização das diversas escalas de pontuação parcial dos objetivos, só tendo significado substantivo no contexto particular do modelo de avaliação em questão, isto é, do conjunto de objetivos, funções de valor e descritores nele considerados. Caso algum destes elementos seja alterado os pesos também se alteram. O que se mantém constante são as taxas de substituição (trade-offs) das pontuações parciais (unidades de valor) entre objetivos definidas pelo decisor. Os pesos operacionalizam assim uma noção de compensação entre objetivos, ou seja, é aceite pelo decisor que a perda de valor num determinado objetivo pode ser compensada pelo ganho de valor noutro objetivo, e vice-versa. A inobservância destes pressupostos em procedimentos de ponderação é considerado por Keeney (1992, pp. 147-148) como "O erro crítico mais comum», o que resulta em pesos completamente arbitrários, que não refletem as preferências dos decisores. De facto, os pesos dos objetivos são frequentemente mal interpretados como sendo tradutores de uma noção de importância intrínseca de valor dos objetivos, o que é incorreto no enquadramento do modelo aditivo de agregação. É exatamente para evitar este tipo de equívocos que os procedimentos de ponderação teoricamente corretos pressupõem que sejam desenvolvidos com referência aos intervalos de variação dos impactos, segundo cada um dos objetivos, e às preferências dos decisores em relação a esses impactos. Uma técnica eficaz para o efeito consiste em utilizar as respostas dos decisores a questões que requerem da parte destes a comparação de atividades fictícias, mas plausíveis, construídas com base na combinação de dois níveis de referência, como sejam o melhor e o pior níveis de impacto, segundo cada um dos objetivos. De entre os procedimentos de ponderação teoricamente corretos existentes, destacam-se os métodos trade-off procedure (Keeney e Raiffa, 1976), swing weighting (apresentado em Edwards (1977) e corrigido em Edwards e 
Barron (1994)) e MACBETH (Bana e Costa e Vansnick (1999) e Bana e Costa et al. (2012)).

Tendo em consideração as características específicas dos Decisores, de formação de base com uma sólida componente quantitativa, os facilitadores escolheram o método trade-off procedure porque consideraram que era o que lhes iria permitir apreender mais facilmente a noção de compensação e o significado substantivo dos pesos dos objetivos (Mateus et al., 2010). Os pesos foram assim calculados através da metodologia que se descreve genericamente nos seguintes passos:

1. Em primeiro lugar, foram criadas 16 alternativas fictícias ao, tantas quanto o número de objetivos fundamentais existentes mais uma, tal que, uma delas mantivesse o status quo em todos os objetivos (ou seja, que tivesse o pior impacto em todos os objetivos) e cada uma das restantes tivesse o melhor impacto segundo um dos objetivos o e o pior impacto (equivalente ao status quo) segundo os restantes objetivos;

2. De seguida, os Decisores ordenaram essas alternativas fictícias por ordem decrescente de atratividade global. Este procedimento foi conduzido de uma forma interativa, através de questões do tipo "qual das alternativas fictícias é preferível?» ou "se apenas fosse possível melhorar um dos objetivos, do status quo para o melhor impacto, qual era o objetivo onde preferia que isso acontecesse?» até se ordenarem todas as alternativas fictícias;

3. Posteriormente, foi pedido aos Decisores que selecionassem uma das alternativas fictícias para servir de alternativa padrão de comparação com as restantes. É aconselhável que esta alternativa seja aquela que foi considerada preferida como resultado do procedimento anterior, de forma a que a atratividade do melhor impacto da alternativa padrão seja sempre preferível ao da alternativa com o qual vai ser comparado, e que tenha um descritor quantitativo contínuo para se poder determinar níveis intermédios entre o melhor impacto e o status quo (o que não seria prático, ou mesmo inexequível, se o objetivo escolhido tivesse um descritor 
qualitativo discreto). Neste caso, os Decisores optaram por escolher o segundo objetivo preferido («1.1 Reduzir os custos de manutenção»), uma vez que consideraram ser mais fácil comparar impactos utilizando como escala de referência a variação dos custos de manutenção em euros/ano;

4. Os Decisores foram então interpelados acerca de "quanto é que a REFER estaria disposta a despender a mais em custos de manutenção (€/ano), para passar do status quo para o melhor impacto segundo cada objetivo?». Isto corresponde, para cada alternativa fictícia em avaliação, a variar o impacto segundo o objetivo 1.1 da alternativa padrão, até os Decisores considerarem as duas alternativas equivalentes em termos de preferência. Por exemplo, para o objetivo "1.2 Reduzir os custos de operação", os Decisores indicaram que a variação de 1,5 milhões de euros/ano em custos de manutenção era equivalente a uma variação de 1,3 milhões de euros/ano em custos de operação (ou seja, consideraram que é preferível reduzir $1 € /$ ano em custos de manutenção do que $1 € /$ ano em custos de operação). Já para o objetivo «2.4.2 Aumentar a atratividade do sistema (mercadorias)» os Decisores consideraram que um aumento 2 milhões de toneladas/ano em mercadorias era equivalente a uma variação de 1,75 milhões de euros/ano em custos de manutenção (ver Tabela 11). Uma forma de auxiliar os Decisores nesta tarefa consistiu em determinar primeiro os trade-offs em euros/ano (de custos de manutenção) para aqueles objetivos que os Decisores consideravam mais fáceis, e para os restantes ir sucessivamente estabelecendo limites inferiores e superiores com base na ordenação relativa em termos de preferência anteriormente construída;

5. Desta forma, foi possível construir 14 relações de equivalência, tantas quanto o número total de objetivos fundamentais $n$ menos um. Cada uma destas relações de equivalência pode ser formalmente enunciada através de uma equação linear do seguinte tipo: 
$\left(\frac{100 \times \text { tradeoff }}{1.500 .000}\right) \times k_{1.1}=100 \times k_{o} \quad \forall o \neq 1.1$

em que, o índice $o$ corresponde ao objetivo fundamental $o(o \neq 1.1)$ de acordo com a Tabela 11 ; tradeoffo corresponde a quanto é que a REFER estaria disposta a despender a mais em custos de manutenção (€/ano), para passar do status quo para o melhor impacto segundo o objetivo fundamental $o$; e $k_{1.1}$ e $k_{o}$ representam os pesos, respetivamente, dos objetivos fundamentais 1.1 e $o$;

6. Finalmente, se se adicionar, ao conjunto de equações lineares definido anteriormente, uma restrição linear que impõe que a soma dos pesos $k_{o}$ dos $n$ objetivos fundamentais totalize 1 , será então possível formar um sistema de equações lineares com um número de equações igual ao número de incógnitas, que são os pesos dos objetivos. A resolução deste sistema de equações permite assim calcular um conjunto de pesos consistente com os tradeoffs entre os objetivos estabelecidos pelos Decisores.

A Tabela 11 apresenta, para cada um dos objetivos fundamentais, os seguintes elementos:

- o status quo (SQ) e o melhor impacto segundo o objetivo em questão;

- $\quad$ as unidades de impacto segundo cada objetivo;

- a ordenação em termos de preferência de cada objetivo;

- quanto é que a REFER estaria disposta a despender a mais em custos de manutenção (€/ano), para passar do status quo para o melhor impacto segundo cada um dos objetivos;

- os pesos dos objetivos, resultantes da aplicação do método de ponderação descrito.

\section{Avaliação dos benefícios globais das atividades}

Após a determinação dos pesos dos objetivos foi possível agregar os benefícios parciais de cada atividade numa pontuação de benefícios globais, aplicando o modelo aditivo apresentado em (1). As pontuações globais das atividades em avaliação (incluídas nos pacotes P2 a P7 de todos os setores) 
foram posteriormente analisadas por setor e depois confrontadas entre os vários setores. Destas análises resultaram algumas discordâncias, por exemplo, em relação à ordenação relativa das atividades por setor ou às pontuações globais das atividades de setores distintos.

Tabela 11: Tradeoffs e pesos dos objetivos fundamentais

\begin{tabular}{|c|c|c|c|c|c|c|}
\hline Objetivos & SQ & Melhor & Unidades & Ord. & Tradeoff & Pesos \\
\hline $\begin{array}{l}\text { 1.1 Reduzir os custos de } \\
\text { manutenção }\end{array}$ & 0 & -1.500 .855 & $€ /$ ano & $1 .^{\circ}$ & 1.500 & $13,2 \%$ \\
\hline $\begin{array}{l}1.2 \text { Reduzir os custos de } \\
\text { operação }\end{array}$ & 0 & -1.500 .000 & $€ /$ ano & $4 .^{\circ}$ & 1.300 & $11,5 \%$ \\
\hline $\begin{array}{l}\text { 1.3 Melhorar a eficiência da } \\
\text { gestão }\end{array}$ & SQ & N1 & & $12 .^{\circ}$ & 200 & $1,8 \%$ \\
\hline 1.4.1 Evitar acidentes pessoais & 0 & -6 & mortos equiv./ano & $6 .^{\circ}$ & 850 & $7,5 \%$ \\
\hline 1.4.2 Evitar acidentes materiais & 0 & -70 & acidentes/ano & $4 .^{\circ}$ & 1.300 & $11,5 \%$ \\
\hline $\begin{array}{l}1.5 \text { Garantir a segurança de } \\
\text { pessoas e bens }\end{array}$ & 0 & $-25 \%$ & atos vandalismo/ano & $7 .^{\circ}$ & 750 & $6,6 \%$ \\
\hline $\begin{array}{l}\text { 2.1 Aumentar a utilização da } \\
\text { infraestrutura }\end{array}$ & 0 & 482.328 & comboios.km/ano & $8 .^{\circ}$ & 500 & $4,4 \%$ \\
\hline 2.2 Reduzir o tempo de trajeto & 0 & 68.112 & comboios.minuto/ano & $11 .^{\circ}$ & 250 & $2,2 \%$ \\
\hline $\begin{array}{l}\text { 2.3 Garantir a continuidade do } \\
\text { serviço }\end{array}$ & 0 & -82.631 & comboios.minuto/ano & $8 .^{\circ}$ & 500 & $4,4 \%$ \\
\hline $\begin{array}{l}\text { 2.4.1 Aumentar a atratividade } \\
\text { (passageiros) }\end{array}$ & 0 & 22.116 .650 & passageiros/ano & $3 .^{\circ}$ & 1.300 & $11,5 \%$ \\
\hline $\begin{array}{l}\text { 2.4.2 Aumentar a atratividade } \\
\text { (mercadorias) }\end{array}$ & 0 & 2.000 .000 & toneladas/ano & $2 .^{\circ}$ & 1.750 & $15,4 \%$ \\
\hline 3.1 Acessibilidade & 0 & 14 & estações & $12 .^{\circ}$ & 250 & $2,2 \%$ \\
\hline 3.2 Ruído & 0 & 7.341 & pessoas & $12 .^{\circ}$ & 350 & $3,1 \%$ \\
\hline 3.3 Intervenções artísticas & 0 & -2 & estações & $15 .^{\circ}$ & 50 & $0,4 \%$ \\
\hline 3.4 Passagens de nível & 0 & -80 & passagens de nível & $10 .^{\circ}$ & 500 & $4,4 \%$ \\
\hline
\end{tabular}

Tradeoffs em milhares de euros/ano

Uma das vantagens da construção de um modelo deste tipo é a de que permite, por um lado, justificar de forma transparente as razões que levaram à atribuição de cada pontuação e, por outro lado, resolver algumas das discordâncias que possam existir no decurso do processo de avaliação, nomeadamente através da revisão de alguns dos parâmetros (por exemplo, pesos, funções de valor ou impactos) que estiveram na base da avaliação efetuada. Uma convicção base da metodologia é a de que o modelo deve representar os dados objetivos do problema e as preferências dos Decisores. Nos casos em que os resultados do modelo não coincidiam com as 
preferências holísticas iniciais dos Decisores em relação ao mérito das atividades, o modelo foi revisitado de forma a verificar se o mesmo estava a representar adequadamente as suas preferências, nomeadamente em termos de objetivos e juízos de valor, até considerarem válidas as recomendações sugeridas pelo modelo. Este processo culminou numa melhor compreensão do problema de decisão e das razões que levaram à pontuação global das atividades tal como sugerida pelo modelo.

As pontuações globais das atividades assim obtidas foram depois normalizadas para que o conjunto de todas as atividades em avaliação correspondesse a um benefício global relativo de 100\%. Desta forma, foi possível determinar o benefício global relativo de cada atividade em relação ao status quo (medido em percentagem do total de benefícios) dividindo a pontuação global dessa atividade pela soma das pontuações globais de todas as atividades. A Figura 6 sintetiza, para cada setor, o somatório dos benefícios globais relativos das atividades incluídas em cada pacote (uma célula a cinzento indica que não foram classificadas quaisquer atividades no respetivo pacote). Assim, por exemplo, para o setor S1, as atividades classificadas no pacote $\mathrm{P} 3$ representam 1,9\% do total dos benefícios, as atividades classificadas no pacote P3 (que inclui também as atividades do pacote P2) representam 4,5\% do total dos benefícios. O conjunto das atividades deste setor S1 representam $31,6 \%$ do total dos benefícios.

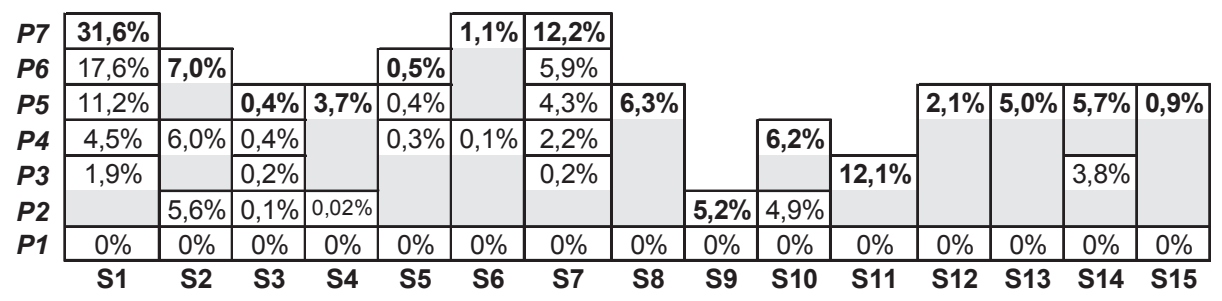

Figura 6: Benefícios globais relativos das atividades

\section{Seleção das atividades a incluir no plano de atividades}

Os recursos são escassos e limitados em qualquer organização. Em especial, a aplicação dos recursos públicos está sujeita a um escrutínio cada vez maior da sociedade, por via das instituições ou da opinião pública e publicada. A 
afetação de recursos deve ser portanto baseada em critérios transparentes de avaliação da eficácia, eficiência e economicidade das atividades que é suposto sustentarem e fundamentada num processo participativo que garanta a qualidade das decisões tomadas e a sua fundamentação perante os restantes atores, internos ou externos à organização.

O método proposto para a determinação das atividades a incluir no Plano consistiu na seleção de um portefólio (subconjunto) de atividades eficiente que não excedesse o orçamento disponível da DGEN para 2006.

Os benefícios globais relativos e os custos a incorrer com cada atividade foram determinados nas etapas metodológicas anteriores. No âmbito de cada setor, a priorização das atividades foi realizada, a um primeiro nível, considerando os pacotes em que foram incluídas, sendo que, nesse âmbito, a realização de qualquer atividade incluída num determinado pacote pressupõe que todas as atividades incluídas em pacotes de nível inferior também sejam realizadas.

Neste contexto, cada estratégia de operacionalização do Plano de Atividades consiste numa qualquer combinação possível de atividades que respeite a regra de priorização anteriormente estabelecida. O número de diferentes estratégias que é possível assim construir compreende desde a estratégia de realizar apenas as atividades incluídas no pacote P1 de cada setor até à estratégia de realizar todas as atividades propostas pelos diversos órgãos da DGEN. O número total de combinações diferentes de atividades que é possível assim gerar é enorme (mais de $1,637 \times 10^{19}$ estratégias distintas), o que torna inexequível qualquer tentativa de comparar diretamente todas as estratégias entre si.

Existem várias abordagens para resolver este problema. Uma delas baseia-se no princípio da priorização das atividades, com base no seu rácio benefício/custo (Bana e Costa et al., 2006; Phillips e Bana e Costa, 2007): primeiro, as atividades são listadas por ordem decrescente do seu rácio benefício/custo; posteriormente, estas atividades são selecionadas pela ordem listada até que não seja possível selecionar mais nenhuma atividade sem que se ultrapasse o limite de recursos disponível. O portefólio de atividades assim construído é constituído pelas atividades com maiores rácios benefício/custo, e 
é um portefólio eficiente, pois não existe outro portefólio de atividades que dê maior benefício global sem custar mais, ou que custe menos e dê o mesmo benefício global. Foi desta forma que se selecionou o portefólio de atividades para o Plano considerando o orçamento disponível pela DGEN para 2006.

Dada a sua simplicidade, este método pode ser facilmente implementado em Excel. Contudo, existe software específico no mercado (Lourenço et al., 2008) que, para além de apresentar variações em relação à forma como o portefólio eficiente de atividades é selecionado e quanto ao tipo de restrições e interações que é possível estabelecer, permite visualizar e interagir, de uma forma amigável, com os decisores, face a alterações em tempo real de qualquer um dos parâmetros do modelo de afetação de recursos (Goodwin e Wright, 2004). Por esta última razão, optou-se por selecionar o software Equity (Catalyze, 2008). A Figura 7 apresenta um dos outputs desta aplicação.

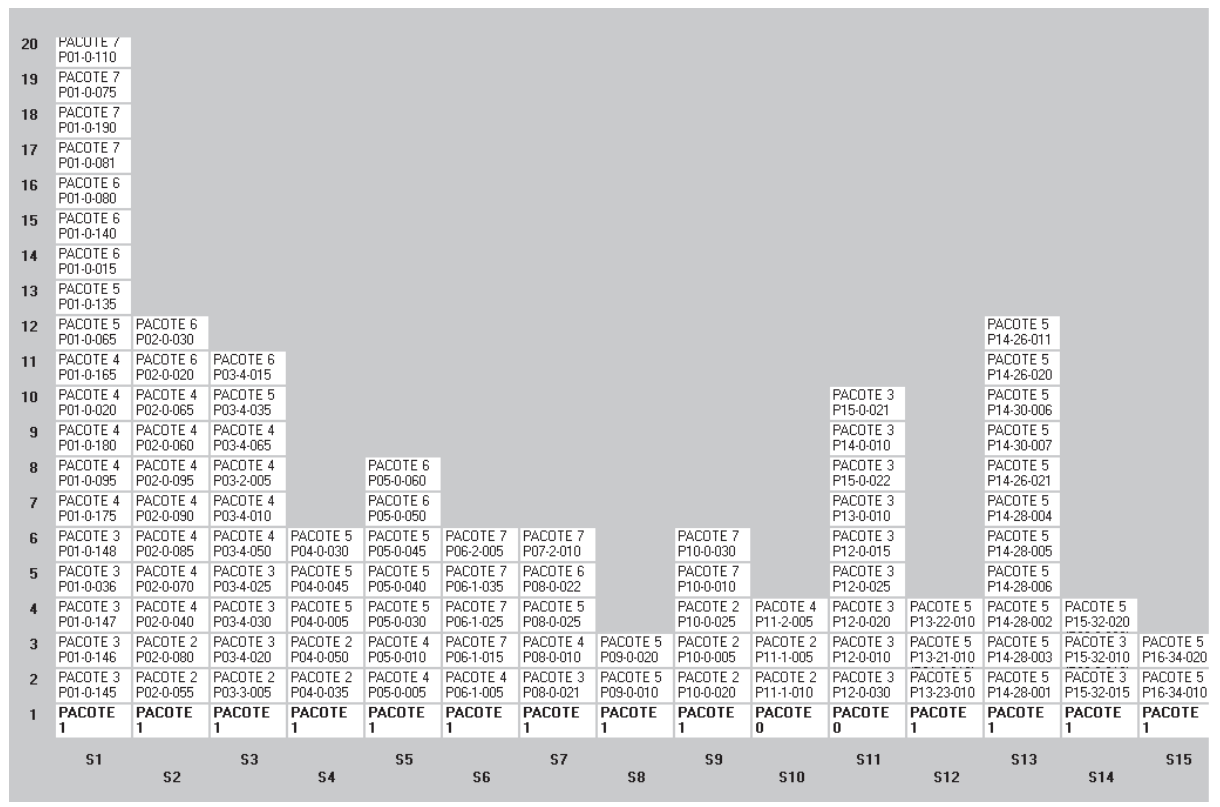

Figura 7: Ordenação das atividades por pacote e, dentro destes, pelo seu rácio benefício/custo

Na Figura 7, os setores são apresentados no eixo horizontal e as atividades, incluídas em cada um dos setores, são apresentadas no eixo vertical. Cada uma das atividades é representada por uma caixa retangular onde se encontram 
descritos a sua designação e o respetivo pacote. A única exceção a esta regra diz respeito às atividades do pacote P1 que, para cada setor, foram agrupadas numa única caixa retangular onde constava simplesmente a designação do respetivo pacote, uma vez que a sua seleção não estava em avaliação. As restantes atividades, incluídas nos pacotes de nível superior, foram previamente priorizadas: primeiro, de acordo com o pacote em que tinham sido classificadas, sendo que as atividades inseridas em pacotes de nível inferior tinham prioridade sobre outras que tivessem sido inseridas em pacotes de nível superior; de seguida, para as atividades que tinham sido classificadas num mesmo pacote, de acordo com o seu rácio benefício/custo, sendo que as atividades com um maior rácio tinham prioridade sobre outras com um rácio inferior. Assim, por exemplo, as atividades do setor S1 foram assim priorizadas: em primeiro lugar, uma vez que nenhuma das atividades tinha sido classificada no pacote $\mathrm{P} 2$, as atividades do pacote $\mathrm{P} 3$ foram ordenadas em função do seu rácio benefício/custo. A atividade P01-0-145 tinha o maior rácio benefício/custo, pelo que deverá ser a primeira atividade a ser realizada segundo este setor. A atividade P01-0-146 apresentava o segundo melhor rácio, pelo que ficou ordenada em segundo lugar. Da mesma forma, as restantes três atividades deste pacote foram priorizadas por ordem decrescente do seu rácio de acordo a sequência P01-0-147, P01-0-036 e P01-0-148. De seguida, foram as atividades do pacote $\mathrm{P} 4$ a ser priorizadas, em função do seu rácio benefício/custo, resultando na ordenação P01-0-175, P01-0-095, P01-0-180, P01-0-020 e P01-0165. Finalmente, as atividades dos pacotes P5, P6 e P7 foram priorizadas, sucessivamente, de acordo com a mesma regra.

Após a estruturação do problema desta forma no software Equity, esta aplicação permite representar graficamente os portefólios de atividades eficientes (ver Figura 8). A área a sombreado representa o «envelope» que define os limites convexos em termos dos benefícios relativos e custos totais a incorrer em 2006 do universo de portefólios distintos que é possível criar face aos dados deste problema. A curva que estabelece o limite superior deste envelope é definida pelo conjunto dos pontos que representam os portefólios eficientes que é possível gerar utilizando a abordagem da priorização anteriormente descrita. De acordo com esta abordagem, o portefólio eficiente a 
selecionar para o Plano de Atividades é o que corresponde ao ponto que se situa imediatamente à esquerda da linha vertical a tracejado, que define o limite orçamental para 2006.

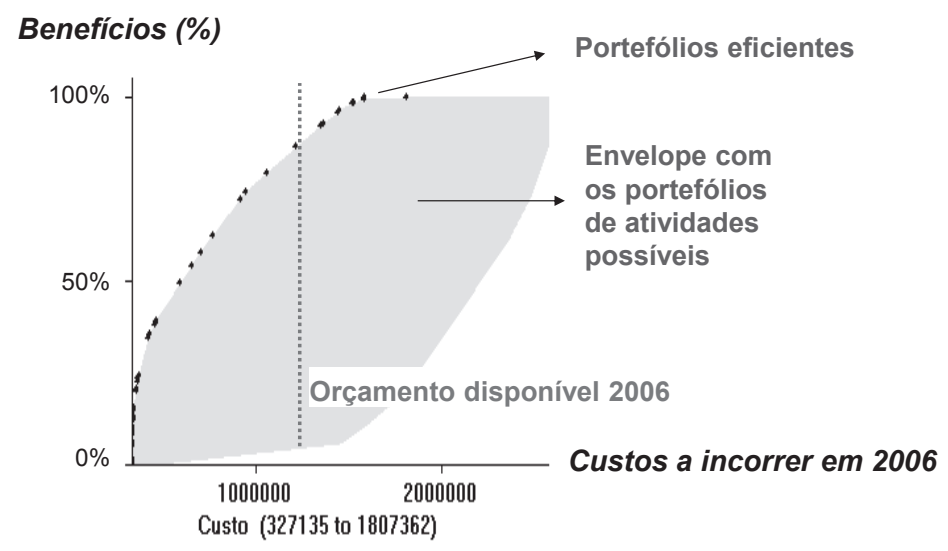

Figura 8: Representação gráfica dos portefólios eficientes no software Equity

A constituição dos portefólios eficientes encontrados pela priorização face a sucessivos aumentos dos limites orçamentais disponíveis pode ser observada numa janela do software Equity (Figura 9). O portefólio eficiente representado na Figura 9 é constituído pelas atividades do setor S1 até à atividade P01-0-065, pelas atividades do pacote P1 dos setores S2 e S3, pelas atividades do setor S4 até à atividade P04-0-005, por todas as atividades do setor S5, pelas atividades do pacote P1 do setor S6, pelas atividades do setor S7 até à atividade P08-0-010, pelas atividades do pacote P1 dos setores S8, S9 e S10, pelas atividades do setor S11 até à atividade P12-0-025, pelas atividades do setor S12 até à atividade P13-21-010 e por todas as atividades dos setores S13, S14 e S15.

\section{Notas finais}

O modelo desenvolvido é uma ferramenta que visa apoiar os decisores da REFER no processo de seleção do portefólio de atividades a incluir no Plano, tendo em consideração os recursos disponíveis na organização para esse efeito. 


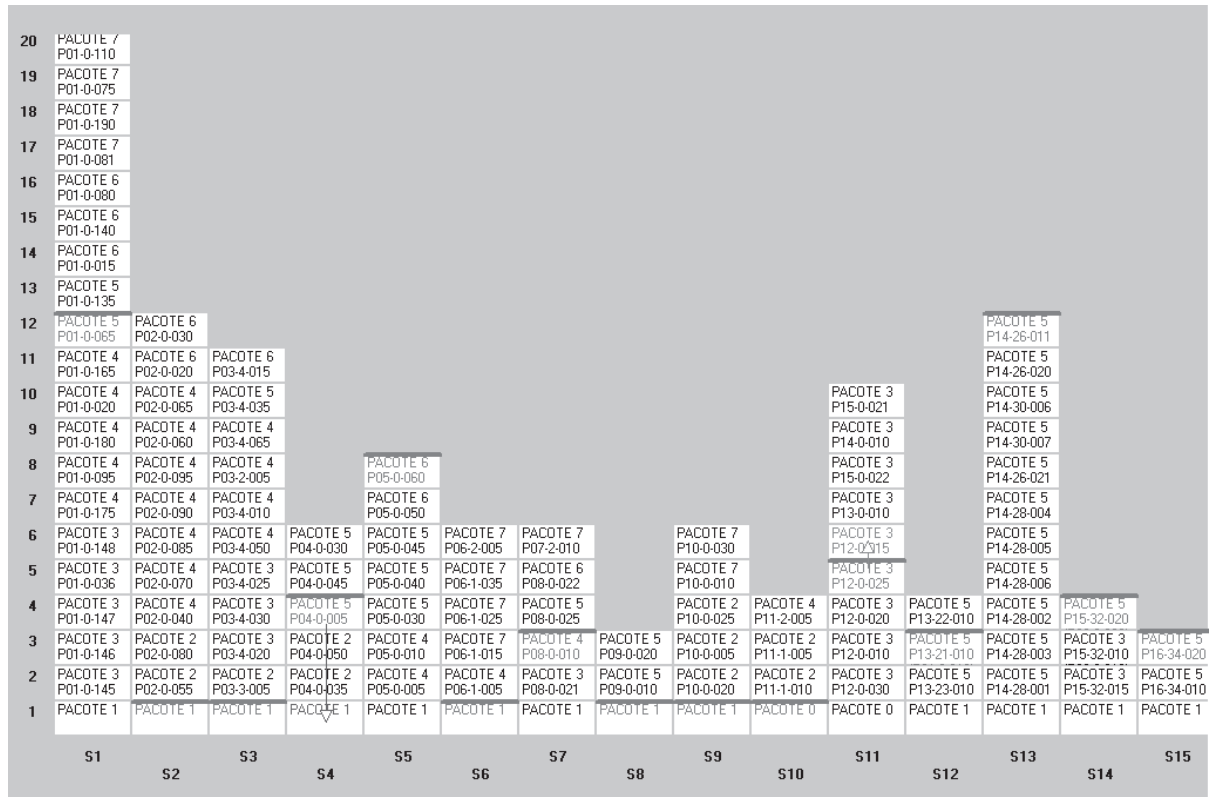

Figura 9: Portefólio de atividades eficiente

A aceitação do modelo e dos respetivos resultados por parte dos participantes é uma das virtudes da abordagem sociotécnica aplicada. Nas palavras de um Diretor da REFER «Os resultados são atingidos por pessoas. Por conseguinte, se o grau de convergência entre os objetivos das pessoas e os objetivos da organização for elevado, o Plano de Atividades tem maiores hipóteses de se tornar uma realidade» (Diogo, 2007, p. 4). Neste âmbito, refirase ainda, a título ilustrativo, uma das reações manifestadas por um dos Decisores relativamente ao processo de apoio à decisão: «Pela primeira vez, em muitos anos, vi numa mesma sala todos os Diretores da REFER, a interagir e discutir sobre os problemas comuns da organização". De facto, o envolvimento dos atores-chave da DGEN desde a definição dos objetivos até à análise e seleção das atividades a integrar no Plano permitiu que os participantes desenvolvessem um sentido de pertença do modelo desenvolvido (Phillips e Bana e Costa, 2007); na realidade, o modelo foi elaborado pelos atores-chave para eles próprios utilizarem como instrumento de afectação de recursos e, posteriormente, na sua componente de avaliação multicritério, como 
ferramenta de monitorização. No entanto, o desenvolvimento de um processo deste tipo, envolvendo diversos participantes com múltiplas perspetivas sobre o problema da REFER, requer uma elevada preparação e sólidos conhecimentos técnicos por parte da equipa de apoio à decisão, tanto para a facilitação das reuniões de grupo como para a aplicação dos métodos e técnicas da análise de decisão e utilização de software especializado.

É importante destacar a forma como o zero da escala de valor de cada objetivo foi definido (Golabi et al., 1981; Bana e Costa et al., 2006; Clemen e Smith, 2009). Na literatura sobre multicritério é usual estabelecer que o valor segundo um determinado objetivo deve ser representado sobre uma escala de intervalos, sendo esta escala invariante a transformações lineares afins (Stevens, 1946). Mas esta transformação não é válida em problemas de afectação multicritério de recursos, uma vez que esta transformação não garante a preservação do ponto zero da escala. Por exemplo, considerem-se três atividades ( $A, B$ e $C$ ) com, respetivamente, 30, 20 e 10 unidades de benefício e 20, 16 e 10 unidades de custo, as suas razões benefício/custo são respetivamente, $r_{A}=1,5(30 / 20), r_{B}=1,25$ (20/16) e $r_{C}=1$ (10/10). Se adicionarmos 50 unidades de benefício a cada uma das atividades, que é uma operação perfeitamente lícita para escalas de intervalos, as razões benefício/custo alteram-se, ficando $r_{A}=4(80 / 20), r_{B}=4,375(70 / 16)$ e $r_{C}=6$ (60/10). Observe-se que a ordem das razões era originalmente $r_{A}>r_{B}>r_{C}$ e que com a adição das 50 unidades de benefício passou a ser $r_{C}>r_{B}>r_{A}$, o que altera completamente a ordem de seleção de atividades a incluir no portefólio. A solução adotada para resolver este problema, no caso da REFER aqui apresentado (Secção 6), passou por considerar que qualquer atividade que não acrescentasse valor nem retirasse valor segundo um determinado objetivo (ou seja, se mantivesse o status quo nesse objetivo) teria uma pontuação de zero unidades de benefício nesse objetivo.

Em último lugar há que realçar que a investigação na área da afetação multicritério de recursos - ou Portfolio Decision Analysis (Salo et al., 2011a e 2011b) - não se esgota na abordagem que foi aplicada na REFER. Efetivamente, a investigação produzida nesta área tem tido uma dinâmica crescente nos últimos tempos, como se pode comprovar pelo elevado número de 
publicações recentes (ver, por exemplo, a revisão da literatura apresentada em Salo et al., 2011c). Entre outros desenvolvimentos, destaca-se a existência de novas ferramentas e abordagens que permitem modelar, de forma direta, interdependências entre atividades, tais como relações de dependência, de sequencialidade (como as descritas na Secção 3) ou de mútua exclusividade entre atividades, sinergias ou antagonismos entre atividades e acomodar restrições de recursos em múltiplos períodos temporais, o que não é possível fazer-se com a metodologia que foi aplicada na REFER. Em problemas em que existe incerteza associada às estimativas de custos e benefícios das atividades bem como, eventualmente, hesitações relativamente aos pesos dos objetivos é sensato analisar a robustez do portefólio de atividades selecionado face à variação simultânea de todos os parâmetros incertos. Refira-se a propósito deste último aspeto que a metodologia proposta inicialmente à REFER incluía a realização de análises de sensibilidade aos parâmetros do modelo, principal razão pela qual se admitiu desde o início que as estimativas dos custos e impactos pudessem ser modeladas através de intervalos de valores (Secção 7).

Para lidar com as situações antes descritas podemos agora recorrer à abordagem e sistema de apoio à decisão denominados Portfolio Robustness Evaluation (PROBE) (Lourenço et al., 2012), que utiliza a programação matemática e algoritmos específicos para formar portefólios eficientes de atividades e para analisar a robustez desses portefólios. É interessante referir que este software também permite considerar custos associados a não financiar atividades, o que poderá ser útil quando a não seleção de uma atividade possa dar lugar, por exemplo, ao pagamento de uma indemnização (Lourenço et al., 2010). Robust Portfolio Modeling (RPM) (Liesiö et al., 2008) foi a primeira abordagem criada para analisar a robustez de portefólios de atividades. RPM considera logo à partida a existência de incerteza em todos os parâmetros do modelo para depois procurar todos os portefólios eficientes de atividades, o que resulta, tipicamente, num número muito elevado de portefólios. Posteriormente, utiliza um processo iterativo, através da aplicação de regras de exclusão e de redução progressiva dos domínios de incerteza dos parâmetros para reduzir o número de portefólios eficientes previamente encontrados até ao 
ponto em que o decisor se sente em condições para selecionar um único portefólio de atividades.

\section{Agradecimentos}

Os autores agradecem à REFER por ter autorizado esta publicação e aos decisores e técnicos que colaboraram no trabalho aqui apresentado, em especial ao Eng. ${ }^{\circ}$ Carrasquinho de Freitas (Diretor-Geral da DGEN). A redação final do artigo beneficiou significativamente dos comentários produzidos por revisores anónimos, aos quais deixamos o nosso agradecimento. Adicionalmente, os autores expressam publicamente o seu agradecimento ao Professor Carlos Bana e Costa pelos ensinamentos ministrados nas desafiantes áreas da análise de decisão e da afetação multicritério de recursos. Por último, agradecem à Fundação para a Ciência e a Tecnologia pelos meios disponibilizados para a sua formação científica e para a elaboração deste trabalho.

\section{Bibliografia}

BANA e COSTA, Carlos António, "Absolute and Relative Evaluation Problematiques: The Concept of Neutral Level and the MCDA Robot Technique", Multicriteria Decision Making: Methods, Algorithms, Applications - Proceedings of the International Workshop, Liblice, Czechoslovakia, 1992a, pp. 7-15.

BANA e COSTA, Carlos António, Structuration, construction et exploitation d'un modèle multicritère d'aide à la décision, Tese de Doutoramento, Universidade Técnica de Lisboa, 1992b.

BANA e COSTA, Carlos António, Processo de apoio à decisão: Actores e acções; estruturação e avaliação, Publicação CESUR, IST, Volume 618, 1993 a.

BANA e COSTA, Carlos António, "Três convicções fundamentais na prática de apoio à decisão", Pesquisa Operacional, 13(1), 1993b, pp. 9-20.

BANA e COSTA, C. A. e Outros, "Metodologia multicritério de apoio à avaliação de propostas em concursos públicos", Casos de Aplicação da Investigação Operacional, McGraw-Hill, 2000, pp. 337-363.

BANA e COSTA, C. A. e Outros, "Multicriteria approach for strategic town planning: the case of Barcelos", Aiding Decisions with Multiple Criteria: Essays in Honour of Bernard Roy, Kluwer Academic Publishers, Dordrecht, 2002, pp. 429-456.

BANA e COSTA, C. A. e Outros, M-MACBETH Versão 1.1 Guia do utilizador, http://www.mmacbeth.com, 2005.

BANA e COSTA, C. A. e Outros, "Prioritisation of public investments in social infrastructures using multicriteria value analysis and decision conferencing: A case study", International Transactions in Operational Research, 13(4), 2006, pp. 279-297. 
BANA e COSTA, C. A. e Outros, "Development of reusable bid evaluation models for the Portuguese Electric Transmission Company", Decision Analysis, 5(1), 2008, pp. 22-42.

BANA e COSTA, C. A. e Outros, "MACBETH", International Journal of Information Technology EDecision Making, 11(2), 2012, pp. 359-387.

BANA e COSTA, C. A. e Outros, "A socio-technical approach for group decision support in public strategic planning: The Pernambuco PPA case", Group Decision and Negotiation, 23(1), 2014, pp. 5-29.

BANA e COSTA, C. A. e VANSNICK, J. C., "MACBETH: an interactive path towards the construction of cardinal value functions", International Transactions in Operational Research, 1(4), 1994, pp. 489-500.

BANA e COSTA, C. A. e VANSNICK, J. C., "The MACBETH approach: Basic ideas, software, and an application", Advances in Decision Analysis, Kluwer Academic Publishers, Dordrecht, 1999, pp. 131-157.

BANXIA, Decision Explorer - User's Guide Version 3.2. Banxia Software Limited, Kendal, http://www.banxia.com, 2002.

BELTON, V. e STEWART, T. J., Multiple Criteria Decision Analysis: An Integrated Approach, Kluwer, Boston, MA, 2002.

CATALYZE, Equity (version 3.4), Catalyze Ltd., Hurley, http://www.catalyze.co.uk, 2008.

CLEMEN, Robert Taylor, Making Hard Decisions: An Introduction to Decision Analysis, Duxbury Press, Belmont, CA, 1996.

CLEMEN, R. T. e SMITH, J. E., "On the choice of baselines in multiattribute portfolio analysis: A cautionary note", Decision Analysis, 6(4), 2009, pp. 256-262.

DIOGO, Alberto de Almeida, "Plano de Actividades e Orçamentos: Realizar mais actividades com os mesmos recursos", Notícias REFER, Ano 11, N. ${ }^{\circ}$ 57, 2007, p. 4.

DOGSON, J. e Outros, DTLR Multi-Criteria Analysis Manual, Office of the Deputy Prime Minister, UK, 2000.

DYER, J. S. e SARIN, R. K., "Measurable multiattribute value functions", Operations Research, 27(4), 1979, pp. 810-822.

EDEN, Colin, "Cognitive mapping", European Journal of Operational Research, 36(1), 1998, pp. $1-13$.

EDEN, C. e SIMPSON, P., "SODA and cognitive mapping in practice", Rational Analysis for a Problematic World: Problem Structuring Methods for Complexity, Uncertainty and Conflict, John Wiley \& Sons, New York, 1989, pp. 43-70.

EDWARDS, Ward, "How to use multiattribute utility measurement for social decisionmaking", IEEE Transactions on Systems, Man and Cybernetics, 7(5), 1977, pp. 326-340.

EDWARDS, W. e BARRON, F. H., "SMARTS and SMARTER: Improved simple methods for multiattribute utility measurement", Organizational Behavior and Human Decision Processes, 60(3), 1994, pp. 306-325.

GOLABI, K. e Outros, "Selecting a portfolio of solar energy projects using multiattribute preference theory", Management Science, 27(2), 1981, pp. 174-189.

GOODWIN, P. e WRIGHT, G., Decision Analysis for Management Judgement, John Wiley \& Sons, Chichester, 2004.

HAMMOND, J. S. e Outros, "The hidden traps in decision making", Harvard Business Review, 84(1), 2006, pp. 118-126. 
KEENEY, Ralph L., Value-focused thinking: A path to creative decision making, Harvard University Press, Cambridge, MA, 1992.

KEENEY, Ralph L., "Developing objectives and attributes", Advances in Decision Analysis: From Foundations to Applications, Cambridge University Press, Cambridge, 2007, pp. 104-128.

KEENEY, R. L. e RAIFFA, H., Decisions with Multiple Objectives: Preferences and Value Tradeoffs, John Wiley \& Sons, New York, 1976.

LIESIÖ, J. e Outros, "Robust portfolio modeling with incomplete cost information and project interdependencies", European Journal of Operational Research, 190(3), 2008, pp. 679-695.

LOURENÇO, J. C. e Outros, "Software packages for multi-criteria resource allocation", IEEE International Engineering Management Conference, Estoril, Portugal, 2008.

LOURENÇO, J. C. e Outros, "Portfolio decision analysis with PROBE: Addressing costs of not financing projects", 12th WSEAS International Conference on Mathematical and Computational Methods in Science and Engineering, University of Algarve, Faro, Portugal, 2010.

LOURENÇO, J. C. e Outros, "PROBE - A multicriteria decision support system for portfolio robustness evaluation", Decision Support Systems, 54(1), 2012, pp. 534-550.

MONTEIRO, José Alves, "O Controlo das Actividades na REFER: Uma importante ajuda para melhorar o nosso desempenho", Notícias REFER, Ano 10, N. ${ }^{\circ} 47,2006$, p.4.

MATEUS, R. e Outros, "Multicriteria decision analysis (MCDA): Central Porto high-speed railway station", European Journal of Operational Research, 187(1), 2008, pp. 1-18.

MATEUS, R. e Outros, "Full disclosure of tender evaluation models: Background and application in Portuguese public procurement", Journal of Purchasing and Supply Management, 16(3), 2010, pp. $206-215$.

NEVES, A. R. e Outros, "A multi-criteria approach to local energy planning: The case of Barreiro municipality", 1st International Conference on Operations Research and Enterprise Systems, Vilamoura, Portugal, 2012.

OLIVEIRA, R. C. e LOURENÇO, J. C., "A multicriteria model for assigning new orders to service suppliers", European Journal of Operational Research, 139(2), 2002, pp. 390-399.

PHILliPS, Lawrence D., "People-centred group decision support", Knowledge-based Management Support Systems, Ellis Horwood, Chichester, 1989, pp. 208-224.

PHILliPS, Lawrence D., "Decision analysis for group decision support", Tackling strategic problems: The role of group decision support, Sage, London, 1990, pp. 142-153.

PHILlIPS, Lawrence D., "Decision conferencing", Advances in Decision Analysis: From Foundations to Applications, Cambridge University Press, Cambridge, 2007, pp. 375-399.

PHILliPS, L. D. e BANA e COSTA, C. A., "Transparent prioritisation, budgeting and resource allocation with multi-criteria decision analysis and decision conferencing", Annals of Operations Research, 154(1), 2007, pp. 51-68.

REFER, Empresa Pública, Manual de Procedimentos da Direcção Geral de Engenharia, 2004.

REFER, Empresa Pública, Relatório de Sustentabilidade, 2005 a.

REFER, Empresa Pública, Relatório e Contas, 2005b.

RUSSO, J. E. e SCHOEMAKER, P. J. H., Decision Traps: The Ten Barriers to Brilliant DecisionMaking and How to Overcome Them, Doubleday, New York, 1989.

SALO, A. e Outros, "Portfolio decision analysis: Improve resource allocation", Analytics (November/December), 2011a, pp. 23-26.

SALO, A. e Outros, Portfolio Decision Analysis: Improved Methods for Resource Allocation, Springer, New York, 2011b. 
SALO, A. e Outros, "An invitation to portfolio decision analysis", Portfolio Decision Analysis: Improved Methods for Resource Allocation, Springer, New York, 2011c, pp. 3-27.

STEVENS, Stanley Smith, "On the theory of scales of measurement", Science, 103(2684), 1946, pp. 677-680.

VON WINTERFELDT, D. e EDWARDS, W., Decision Analysis and Behavioural Research, Cambridge University Press, Cambridge, MA, 1986. 